This is the author's final, peer-reviewed manuscript as accepted for publication. The publisher-formatted version may be available through the publisher's web site or your institution's library.

\title{
Electrochemical protease biosensor based on enhanced AC voltammetry using carbon nanofiber nanoelectrode arrays
}

Luxi Z. Swisher, Lateef U. Syed, Allan M. Prior, Foram R. Madiyar, Kyle R. Carlson, Thu A. Nguyen, Duy H. Hua, Jun Li

\section{How to cite this manuscript}

If you make reference to this version of the manuscript, use the following information:

Swisher, L. Z., Syed, L. U., Prior, A. M., Madiyar, F. R., Carlson, K. R., Nguyen, T. A., ... Li, J. (2013). Electrochemical protease biosensor based on enhanced AC voltammetry using carbon nanofiber nanoelectrode arrays. Retrieved from http://krex.ksu.edu

\section{Published Version Information}

Citation: Swisher, L. Z., Syed, L. U., Prior, A. M., Madiyar, F. R., Carlson, K. R., Nguyen, T. A., ... Li, J. (2013). Electrochemical protease biosensor based on enhanced AC voltammetry using carbon nanofiber nanoelectrode arrays. The Journal of Physical Chemistry C, 117(8), 4268-4277.

Copyright: @ 2013 American Chemical Society

Digital Object Identifier (DOI): doi:10.1021/jp312031u

Publisher's Link: http://pubs.acs.org/doi/abs/10.1021/jp312031u

This item was retrieved from the K-State Research Exchange (K-REx), the institutional repository of Kansas State University. K-REx is available at http://krex.ksu.edu 


\section{Electrochemical Protease Biosensor Based on}

\section{Enhanced AC Voltammetry Using Carbon \\ Nanofiber Nanoelectrode Arrays}

Luxi Z. Swisher ${ }^{a}$, Lateef U. Syed ${ }^{a}$, Allan M. Prior ${ }^{a}$, Foram R. Madiyar $^{a}$, Kyle R. Carlson ${ }^{a}$, Thu A.

Nguyen ${ }^{b}$, Duy H. Hua ${ }^{a}$, Jun $L_{i} *^{a}$

${ }^{\mathrm{a}}$ Department of Chemistry, Kansas State University, Manhattan, Kansas 66506, United States;

${ }^{b}$ Department of Diagnostic Medicine/Pathobiology, College of Veterinary Medicine, Kansas

State University, Manhattan, Kansas 66506, United States

Corresponding author:

Telephone number: (785) 532-0955

Fax number: (785) 532-6666

Email: junli@ksu.edu 


\begin{abstract}
We report an electrochemical method for measuring the activity of proteases using nanoelectrode arrays (NEAs) fabricated with vertically aligned carbon nanofibers (VACNFs). The VACNFs of $\sim 150 \mathrm{~nm}$ in diameter and 3 to $5 \mu \mathrm{m}$ in length were grown on conductive substrates and encapsulated in $\mathrm{SiO}_{2}$ matrix. After polishing and plasma etching, controlled VACNF tips are exposed to form an embedded VACNF NEA. Two types of tetrapeptides specific to cancermediated proteases legumain and cathepsin B are covalently attached to the exposed VACNF tip, with a ferrocene $(\mathrm{Fc})$ moiety linked at the distal end. The redox signal of Fc can be measured with AC voltammetry (ACV) at $\sim 1 \mathrm{kHz}$ frequency on VACNF NEAs, showing distinct properties from macroscopic glassy carbon electrodes due to VACNF's unique interior structure. The enhanced ACV properties enable the kinetic measurements of proteolytic cleavage of the surface-attached tetrapeptides by proteases, further validated with a fluorescence assay. The data can be analyzed with a heterogeneous Michaelis-Menten model, giving "specificity constant" $k_{\text {cat }} / \mathrm{K}_{\mathrm{m}}$ as $(4.3 \pm 0.8) \times 10^{4} \mathrm{M}^{-1} \mathrm{~s}^{-1}$ for cathepsin $\mathrm{B}$ and $(1.13 \pm 0.38) \times 10^{4} \mathrm{M}^{-1} \mathrm{~s}^{-1}$ for legumain. This method could be developed as portable multiplex electronic techniques for rapid cancer diagnosis and treatment monitoring.
\end{abstract}

Keywords: nanoelectrode array, legumain, cathepsin B, enzymatic kinetics, AC voltammetry 


\section{Introduction}

Proteases, the proteolytic processing proteins, are ubiquitous in living organisms and regulate a multitude of cellular processes including the cell cycle, hormone activation, apoptosis and angiogenesis. $^{1-3}$ The cysteine protease legumain, also known as asparaginyl endopeptidase (AEP), has a strict specificity for hydrolysis of asparaginyl bonds. ${ }^{4}$ It is highly expressed in macrophages, on the cell surfaces and membranous vesicles in the metastatic and invasive solid tumors where it activates other proteases such as cathepsin $\mathrm{B}, \mathrm{H}$ and $\mathrm{L}$, that have both elastinolytic and collagenolytic activities. ${ }^{5-7}$ In breast cancer, several recent studies have shown that absence of the cysteine protease inhibitor leads to increased growth and metastasis. ${ }^{8}$ However, overexpression of those cysteine proteases was not found in the normal tissue. Thus, rapid detection of the presence and activity of cancer-mediated proteases (i.e. legumain and cathepsin B), should be developed for enhancement of treatment. ${ }^{9}$

Traditional methods for enzyme activity study include gel electrophoresis, high-performance liquid chromatography (HPLC), enzyme-linked immunosorbent assay (ELISA) and optical methods. ${ }^{10-13}$ These methods require specific synthesis of peptides, fluorescent labels and sophisticated instrumentations, which are high-cost and time-consuming. Radioimmunoassay (RIA) had been widely used as an highly sensitive detection method but is diminished nowadays due to health safety and environment concerns. ${ }^{14}$ Simple rapid electronic and/or electrochemical methods to detect enzyme activities are thus important in developing portable systems for pointof-care diagnosis and treatment monitoring of diseases such as cancers. Recently, electrochemical methods using cyclic voltammetric (CV) measurements of redox-labeled peptides attached on macroscopic gold electrodes have been demonstrated in detecting highactivity proteases such as trypsin, thrombin and plasmin. ${ }^{15-16}$ Due to the localized sensing mechanism, an array of electrodes functionalized with different peptides could potentially detect 
multiple enzymes in a small sample volume. However, electrochemical detection of proteases that are more relevant to cancers, such as legumain and cathepsin B, has not been reported. These enzymes have much lower catalytic activity, making the measurement more difficult. Here we focus on a new electrochemical technique enabled by nanostructured electrodes that can successfully detect these enzymes.

It is well known that reducing the electrode size can dramatically enhance the detection sensitivity and temporal resolution of electrochemical measurements. ${ }^{17-18}$ This trend extends from the scale of microns to nanometers. Well-separated nanoelectrode arrays (NEAs), either in regular pattern or in random distributions (also referred to as nanoelectrode ensembles (NEEs)), have attracted extensive interests for highly sensitive electroanalysis, measuring fast electrochemical kinetics, and biosensing. ${ }^{19-21}$ Fabrication methods such as nanosphere lithography and E-beam lithography have been developed for the well-ordered NEAs. ${ }^{22-23}$ Carbon based NEAs are particularly attractive for biosensors due to the wider applicable potential window and ease in biofunctionalization through robust covalent attachment. Development in this area, however, has been limited by the lack of readily available methods to fabricate reliable NEAs. Recent research in carbon nanotechnology has provided a method to fabricate wellcontrolled NEAs using vertically aligned carbon nanofibers (VACNFs) embedded in insulating materials. ${ }^{24-26}$ Both precisely patterned and randomly distributed carbon nanofibers (CNFs) with the average diameter of 50-200 $\mathrm{nm}$ and uniform vertical alignment have been fabricated on 4" $\mathrm{Si}$ wafers ${ }^{27}$ and can be mass-produced into robust NEAs on individually addressed microelectrodes forming an "array-in-array" format. Various applications of VACNF NEAs with and without further encapsulation of insulating materials have been demonstrated for various biosensing or biomedical applications, including DNA hybridization analysis, ${ }^{28}$ glucose detection, ${ }^{25}$ electrochemical sensing of neurotransmitters, ${ }^{29}$ neural electrical recording, ${ }^{30}$ and gene delivery. ${ }^{31}$ 
Here we employ the embedded VACNF NEAs for enzymatic studies. The $\mathrm{SiO}_{2}$ matrix was selectively etched by plasma etching to expose $\sim 50-200 \mathrm{~nm}$ long CNF tips over the surface (as shown in Figure S1 in supporting Information). Specific peptide substrates were functionalized at the exposed CNF tips and subjected to proteolysis by proteases. The small radius of the CNF tips $(\sim 50-100 \mathrm{~nm})$ protruding over the $\mathrm{SiO}_{2}$ matrix makes it easier for enzymes to access to the peptides, avoiding the steric hindrance that is normally encountered on macroscopic surfaces.

Generally, CV measurements of bulk redox species using embedded VACNF NEAs show characteristic sigmoidal curves, ${ }^{28,32}$ in which the tiny CNF tips carry much higher current densities than macro- or micro-electrodes. This feature indicates one of the predicted benefits of nanoelectrodes due to the nonlinear radial diffusion of redox species to the electrode surface. ${ }^{33}$ The NEA also presents much smaller electrochemical cell time constant which allows the electrochemical measurement to be carried out at a much higher speed. These properties make NEAs attractive for rapid high-sensitivity biosensing applications.

Recently, we discovered that the electrochemical measurements on VACNF NEAs can be significantly improved by applying an alternating current (AC) voltage bias on the direct current (DC) ramps in the common CV measurement, i.e. by using AC voltammetry (ACV). ${ }^{34} \mathrm{An}$ anomalously high electron transfer rate was obtained with redox-active Fc molecules attached to the exposed CNF tips of the embedded NEAs. ${ }^{34}$ This was attributed to the unique conically stacked graphitic structure of the CNFs, which opened a new capacitive pathway for AC current. As a result, ACV on VACNF NEAs can be carried out at much higher AC frequency (at $\mathrm{kHz}$ ) than $<100 \mathrm{~Hz}$ on macroscopic glassy carbon electrodes (GCEs). Since the magnitude of the signal in ACV, i.e. AC current amplitude, increases monotonically with the AC frequency at $<1$ $\mathrm{kHz}$, the detection sensitivity can be greatly enhanced using VACNF NEAs. The ACV is particularly advantageous over common $\mathrm{CV}$ for measuring small quantities of surface-attached 
redox molecules since the electrons can be shuffled back and forth for many times between the electrode and each adsorbed molecules. Here, we report the application of this property on detection of the enzymatic activities of legumain and cathepsin B by monitoring the kinetic decrease of the ACV signals of $\mathrm{Fc}$ attached to the CNF tip through a specific peptide linker during proteolysis. The data are well explained with the Michaelis-Menten heterogeneous enzymatic model.

\section{Experimental Section}

Apparatus and Reagents. The electrochemical measurements were conducted on a model 440A electrochemical analyzer ( $\mathrm{CH}$ Instruments, Austin, TX). Fluorescence assay was performed on GloMax-Multi+ Microplate Multimode Reader (Promega Corporation, Madison, WI). A 96well black polystyrene plate in the fluorescent measurement was from Whatman (Picataway, NJ). 3-Aminopropyl-triethoxysilane (APTES), 2-(2-methoxyethoxy)ethoxyacetic acid, 1-ethyl-3-(3dimethylaminopropyl)carbodiimide hydrochloride (EDC), 1-hydroxy-2,5-dioxopyrrolidine-3sulfonic acid sodium salt (sulfo-NHS), sodium hydroxides, and 6-amino-1-hexanol were purchased from Sigma-Aldrich (Saint Louis, MO). 2-(4-Morpholino)ethane sulfonic acid (MES) and dithiothreitol (DTT) were purchased from Thermo Fisher Scientific (Fair Lawn, NJ). Recombinant human legumain/asparaginyl endopeptidase (molecular weight of $49 \mathrm{kDa}$ ) and recombinant human cathepsin B (molecular weight of $29 \mathrm{kDa}$ ) were acquired from $\mathrm{R} \& \mathrm{D}$ Systems Inc. (Minneapolis, MN). Before use for enzymatic reactions, legumain was activated in an activation buffer, consisting of $50 \mathrm{mM} \mathrm{CH}_{3} \mathrm{COONa}$ ( $\mathrm{pH} 4.0$, adjusted by adding acetic acid) and $100 \mathrm{mM} \mathrm{NaCl}$. Cathepsin B was activated in an activation buffer of $5 \mathrm{mM}$ DTT and $25 \mathrm{mM}$ MES (pH 5.0). Substrates Z-Ala-Ala-Asn-AMC and Z-Leu-Arg-AMC for fluorescence assay were obtained from Bachem (Torrance, CA). All aqueous solutions were prepared using 18.2 
$\mathrm{M} \Omega$-cm resistivity deionized (DI) water from a bench-top water purifier (Barnstead EASYpure II RF/UV, Model D7035, Thermo Scientific, Asheville, NC).

\section{Synthesis of Ferrocene-appended Tetrapeptides for Enzyme Cleavage. Ferrocene-} appended tetrapeptide for legumain cleavage (i.e. $\mathrm{H}_{2} \mathrm{~N}-\left(\mathrm{CH}_{2}\right)_{4}-\mathrm{CO}$-Ala-Ala-Asn-Leu-NH- $\mathrm{CH}_{2}-$ Fc) was synthesized following a sequence of reactions described in Figure S2. In brief, H-Leu-2ClTrt-resin (Peptide International Inc., Louisville, KY) was converted to H-Ala-Ala-Asn-Leu-2ClTrt-resin using a microwave peptide synthesizer (CEM Inc., Matthews, NC) by the sequence of reactions: (1) coupling with Fmoc-Asn-OH, $O$-(benzotriazol-1-yl)- $N, N, N^{\prime}, N^{\prime}$-tetramethyluronium hexafluorophosphate (HBTU), and diisopropylethylamine (DIEA) in DMF; (2) removal of the Fmoc protecting group with 20\% piperidine in DMF; and (3) similarly, coupling with Fmoc-Ala$\mathrm{OH}$ and removal of Fmoc twice using the same reagents as described above. H-Ala-Ala-AsnLeu-2-ClTrt-resin was cleaved with trifluoroacetic acid (TFA), triisopropylsilane (TIPS), and water (95:2.5:2.5) to give H-Ala-Ala-Asn-Leu-OH, which upon protection of the amino function with di-t-butyl dicarbonate $\left(\mathrm{Boc}_{2} \mathrm{O}\right)$ followed by the coupling with aminomethylferrocene ${ }^{35}$ and 2-(7-aza-1H-benzotriazole-1-yl)-1,1,3,3-tetramethyluronium hexafluorophosphate (HATU) afforded Boc-Ala-Ala-Asn-Leu-NHCH${ }_{2} \mathrm{Fc}$. Deprotection of the aforementioned tetrapeptide ferrocene with $10 \%$ TFA in dichloromethane at $25^{\circ} \mathrm{C}$ for 30 minutes, followed by condensation with $N$-Boc-5-aminovaleic acid and HATU in DMF, and removal of the Boc protecting group with $10 \%$ TFA in dichloromethane furnished $\mathrm{H}_{2} \mathrm{~N}-\left(\mathrm{CH}_{2}\right)_{4} \mathrm{CO}$-Ala-Ala-Asn-Leu- $\mathrm{NHCH}_{2}-\mathrm{Fc}$. Ferrocene-labeled tetrapeptide substrate for cathepsin B cleavage (i.e. $\mathrm{H}_{2} \mathrm{~N}-\left(\mathrm{CH}_{2}\right)_{4}$-CO-Leu-ArgPhe-Gly-NH- $\mathrm{CH}_{2}-\mathrm{Fc}$ ) was synthesized using a synthetic scheme similar to the aforementioned one and the details are described in Figure S3.

Fabrication of VACNF NEAs. The NEAs were fabricated by encapsulating VACNFs in $\mathrm{SiO}_{2}$ matrix on a silicon chip using a similar method described in previous papers. ${ }^{24,36}$ Briefly, 
VACNFs of an average length of $\sim 5 \mu \mathrm{m}$ were grown on $\sim 100 \mathrm{~nm}$ Cr coated Si substrate using a DC-biased plasma enhanced chemical vapor deposition (PECVD) system (Aixtron, CA). A thin nickel film of $\sim 22 \mathrm{~nm}$ was used as the catalyst to promote CNF growth. The electric field helped to align the CNF vertically on the substrate surface. Cross-sectional SEM images indicate that about $90 \%$ of the CNF have the length of 4 to 6 microns. The CNFs have the diameter distributed from $\sim 100$ to $200 \mathrm{~nm}$ and are well separated from each other, with an average distance of $\sim 300$ to $400 \mathrm{~nm}$. Dielectric $\mathrm{SiO}_{2}$ was deposited using chemical vapor deposition (CVD) from vaporphase precursor tetraethylorthosilicate (TEOS) to fully encapsulate the bottom $\mathrm{Cr}$ metal contact layer and each individual CNFs. Mechanical polishing was applied using $0.3 \mu \mathrm{m}$ alumina slurry to produce a flat surface. Reactive ion etching (RIE) with a mixture of $\mathrm{CHF}_{3}$ and $\mathrm{O}_{2}$ gases was then performed with NRE-3000 (Nano-Master Inc., Austin, TX) to selectively etch away desired amount of $\mathrm{SiO}_{2}$. It can be controlled to expose $20 \%$ to $60 \%$ of the CNF tips based on the length variation. A typical VACNF NEA in this study consists of randomly distributed CNF tips with an average CNF diameter of $\sim 100-200 \mathrm{~nm}$ and an average spacing over $\sim 1 \mu \mathrm{m}$ (corresponding to a density of $\left.\sim(1-10) \times 10^{7} \mathrm{CNFs}-\mathrm{cm}^{-2}\right)$. As shown in Figure S1, the length of exposed CNF tips was controlled at $\sim 50-300 \mathrm{~nm}$ by varying the RIE time to selectively remove $\mathrm{SiO}_{2}$.

Electrode Pre-conditioning. Before each use, VACNF NEAs were further polished with 0.05 $\mu \mathrm{m} \gamma$-alumina slurry on napless polishing cloth (Buehler, Lake Bluff, IL) for 5-15 minutes, followed by rinsing with deionized water. The VACNF NEAs were then electrochemically activated by etching in $1.0 \mathrm{M} \mathrm{NaOH}$ solution using four cycles of $\mathrm{CV}$ in a potential range of $0.10 \mathrm{~V}$ to $1.20 \mathrm{~V}$ (vs. $\mathrm{Ag} / \mathrm{AgCl}(3 \mathrm{M} \mathrm{KCl}))$ at a scan rate of $50 \mathrm{mV} \cdot{ }^{-1}$.

Passivation of the $\mathrm{SiO}_{2}$ Surface of the VACNF NEA Chip. To reduce nonspecific adsorption, the $\mathrm{SiO}_{2}$ surface of the VACNF NEAs was first passivated with protective moieties containing ethylene glycol. The chip was immersed in an $8 \mathrm{~g} \mathrm{~L}^{-1}$ solution of APTES in ethanol 
for 20 minutes to produce a primary amine derivatized surface. The chip was treated with $50 \mu \mathrm{L}$ solution of $0.1 \mathrm{mM}$ of 2-(2-methoxyethoxy)ethoxyacetic acid, $100 \mathrm{~g} \mathrm{~L}^{-1}$ of EDC and $50 \mathrm{~g} \mathrm{~L}^{-1}$ of sulfo-NHS, and incubated at room temperature for 2 hours in an enclosed chamber (Arrayit, CA). The carboxylic acid group of 2-(2-methoxyethoxy)ethoxyacetic acid formed an amide bond with the amino function on the chip surface, leaving ethylene glycol moiety covering the surface. The molecules attached to the CNF tips were then removed by electrochemical etching at $1.2 \mathrm{~V}$ (vs. $\mathrm{Ag} / \mathrm{AgCl}(3 \mathrm{M} \mathrm{KCl}))$ for 20 seconds in $1.0 \mathrm{M} \mathrm{NaOH}$ solution. This process regenerated clean CNF tips which contain abundant carboxylic acid functional groups.

Functionalization of the VACNF NEA Chip. The tetrapeptide $\mathrm{H}_{2} \mathrm{~N}-\left(\mathrm{CH}_{2}\right)_{4}$-CO-Ala-AlaAsn-Leu-NHCH$H_{2}-\mathrm{Fc}$ for legumain study or $\mathrm{H}_{2} \mathrm{~N}-\left(\mathrm{CH}_{2}\right)_{4}-\mathrm{CO}$-Leu-Arg-Phe-Gly-NH- $\mathrm{CH}_{2}-\mathrm{Fc}$ for cathepsin B study was covalently linked to the VACNF NEA by forming amide bond facilitated by EDC and sulfo-NHS. Typically, a solution of $10 \mu \mathrm{L}$ of $10 \mathrm{mM}$ tetrapeptide mixed with $90 \mu \mathrm{L}$ of $10 \mathrm{~g} \mathrm{~L}^{-1}$ EDC and sulfo-NHS was applied onto the electrochemically activated VACNF NEA chip and incubated in the enclosed Arrayit chamber at room temperature for 2 hours. Control experiments and HPLC-MS characterization (see Supporting Information) confirmed that only the end $-\mathrm{NH}_{2}$ group of the tetrapeptide formed amide bond with the carboxylic acid group on the VACNF NEA. The $-\mathrm{NH}_{2}$ and $\mathrm{NH}$ functions in asparagine and arginine moieties in the peptide do not react with the carboxylic acid group under the reaction conditions. In order to stabilize the electronic signal, the CNF electrode surface was further dipped into a solution of $5 \mathrm{~mL}$ of $1 \mathrm{mM}$ 6-amino-1-hexanol containing $5 \mathrm{~g} \mathrm{~L}^{-1}$ EDC and $2 \mathrm{~g} \mathrm{~L}^{-1}$ sulfo-NHS so that the unreacted-COOH sites were linked with 6-aminohexanol.

Electrochemical Measurements. The electrochemical measurements were performed in a TEFLON cell with a total volume of $250 \mu \mathrm{L}$. The cell was sealed against a VACNF NEA chip with a 3-mm i.d. O-ring in a three-electrode configuration with the VACNF NEA as the working 
electrode, an $\mathrm{Ag} / \mathrm{AgCl}(3 \mathrm{M} \mathrm{KCl})$ reference electrode and a coiled $\mathrm{Pt}$ wire as the counter electrode. The electrolyte solutions were consisted of $50 \mathrm{mM}$ MES $(\mathrm{pH}=5.0)$ and $250 \mathrm{mM} \mathrm{NaCl}$ for legumain experiment and $25 \mathrm{mM}$ MES $(\mathrm{pH}=5.0)$ for cathepsin $\mathrm{B}$ experiment. The average $\mathrm{AC}$ current was measured by applying an $\mathrm{AC}$ voltage bias on the DC staircase waveform with the potential sweeping from -0.05 to $+0.65 \mathrm{~V}$ for legumain experiment and $-0.1 \mathrm{~V}$ to $+0.75 \mathrm{~V}$ for cathepsin $\mathrm{B}$ experiment, both at $10 \mathrm{mV} \cdot \mathrm{s}^{-1}$ scan rate. The parameters including $\mathrm{AC}$ voltage amplitude and frequency were varied in specific experiments and specified as the results are presented in later sections.

Validation of the Enzyme Activities with Other Biochemical Methods. The activities of the enzymes vary significantly from batch to batch and are very sensitive to the environment and storage conditions. To reduce the errors, all enzymes were first validated with an established fluorescence-based biochemical method before each electrochemical experiment. The legumain activity was measured with a kinetic fluorescence assay using a commercial substrate Z-Ala-AlaAsn-AMC which gave strong fluorescence after cleavage at the site between asparagine and AMC dye. The substrate Z-Leu-Arg-AMC was used in the fluorescence assay for cathepsin B activity measurement. The cleavage at the site between arginine and AMC dye released the AMC from quenching by the carbonyl group and showed increased fluorescence intensity.

\section{Results and Discussion}

The Design and Electrochemical Characterization of VACNF NEAs for Protease

Detection. Scheme 1 shows the structure of an embedded VACNF NEA covalently attached with Fc-linked peptides at the exposed CNF tips. The Fc moiety at the distal end provides a reliable redox signal at $\sim 0.25 \mathrm{~V}$ vs. $\mathrm{Ag} / \mathrm{AgCl}(3 \mathrm{M} \mathrm{KCl})$ in $\mathrm{ACV}$ measurements. Upon supplied with the specific protease, the peptide is expected to be cleaved at the particular site. As a result, the Fc 
moiety is released from the electrode surface into the bulk solution, causing the redox signal to decrease. The kinetic of the enzymatic reaction at the electrode surface will be monitored by continuously repeated ACV measurements. The advantage of this method is that the appended Fc moiety provides a characteristic faradaic signal which can be easily separated from the unstable nonfaradaic background and other interfering redox signals. The key for this method is that the Fc signal needs to be relatively large and stable over the period of the kinetic measurements (up to $\sim 1$ hour) and the ACV measurement at each point is fast enough to provide $\sim 1$ minute (or less) of temporal resolution. This may become challenging for enzymes requiring long peptide substrate sequences for specific recognition. The $\mathrm{Fc}$ signal involves electron transfer between $\mathrm{Fc}$ molecule and the electrode surface, which is highly sensitive to the Fc-surface distance and the molecular packing of the peptides on the electrode surface. Thus the electrochemical properties of Fc-linked peptide attached on VACNF NEAs need to be carefully characterized.

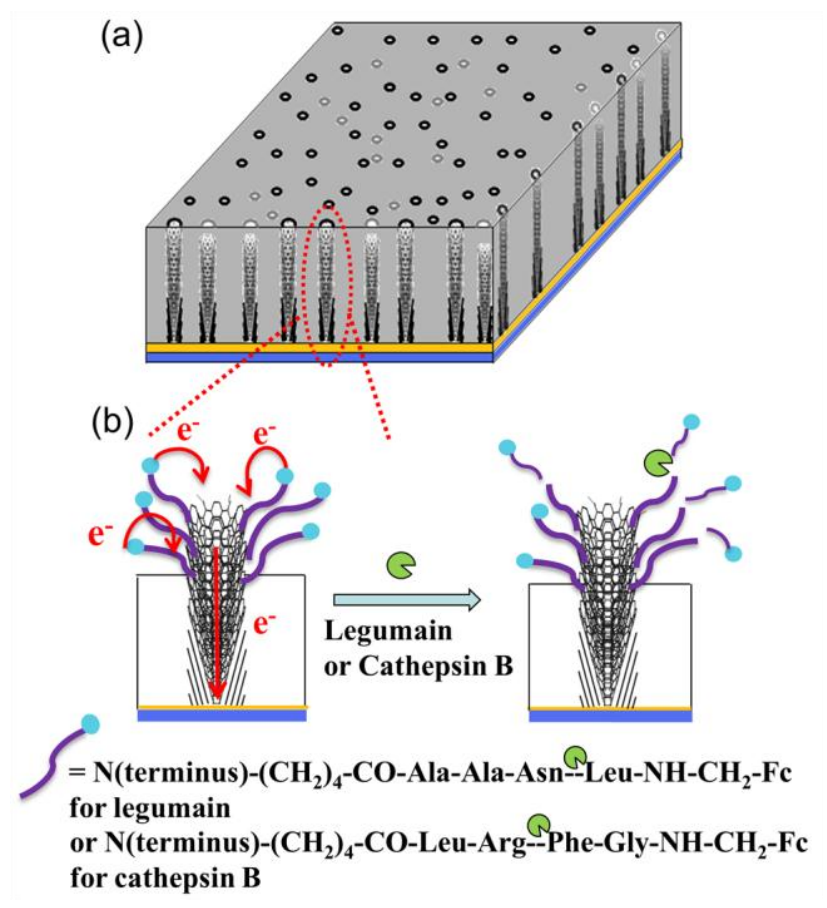


Scheme 1. Schematic diagram of the cleavage of Fc-linked tetrapeptides at the VACNF NEA tip by specific proteases. (a) A random VACNF array embedded in the $\mathrm{SiO}_{2}$ matrix. (b) Electron transfer from appended ferrocene at the distal end of the peptide to the underlying metal film electrode through the VACNFs and the loss of the electrochemical signal from ferrocene due to the cleavage of the peptide at specific sites.

Figure 1 shows the comparison of ACVs of a macro-GCE and a VACNF NEA, both functionalized with the tetrapeptide $\mathrm{H}_{2} \mathrm{~N}-\left(\mathrm{CH}_{2}\right)_{4}$ - CO-Ala-Ala-Asn-Leu- $\mathrm{NHCH}_{2}-\mathrm{Fc}$ to be used for legumain study. A peak current was observed at $\sim 0.2 \mathrm{~V}$ vs. $\mathrm{Ag} / \mathrm{AgCl}(3 \mathrm{M} \mathrm{KCl})$ for both electrodes. The amplitude of the peak current density $\left(i_{p}\right)$ in the ACVs with macro-GCE increased from $\sim 1.0 \times 10^{-7} \mathrm{~A} \cdot \mathrm{mm}^{-2}$ at $10 \mathrm{~Hz}$ to $\sim 2.0 \times 10^{-7} \mathrm{~A} \cdot \mathrm{mm}^{-2}$ at $40 \mathrm{~Hz}$, but then dropped to zero at $1500 \mathrm{~Hz}$. At the meantime, the background signal steadily increased from $\sim 4.7 \times 10^{-7}$, to $1.8 \times 10^{-6}$ and $2.8 \times 10^{-6} \mathrm{~A} \cdot \mathrm{mm}^{-2}$, respectively. In contrast, although the $i_{p}$ of ACV with VACNF NEAs was not measurable at $10 \mathrm{~Hz}$ and $40 \mathrm{~Hz}$, it rose clearly above the background at $1500 \mathrm{~Hz}$, giving $\sim 2.0 \times 10^{-8} \mathrm{~A} \cdot \mathrm{mm}^{-2}$. Obviously, VACNF NEAs allowed the Fc signal to be detected at much higher frequency. It is noteworthy that the current density in Figure 1 was calculated with the geometric electrode surface area. As shown in Figure S1, the actual exposed CNF surface area in the VACNF NEA is more than $\sim 100$ times less than the geometric surface area. Hence the real current density at the CNF tip is at least 10 times higher than that at the GCE. Generally, the electrochemical signal is very sensitive to Fc-surface distance since the electron transfer rate decays exponentially versus the Fc-surface distance. Hence electrochemical sensors based on redox reactions normally use linker molecules less than $2 \mathrm{~nm}$ in length. Here, the electron transfer on both GCEs and VACNF NEAs was not significantly affected by the tetrapeptide and 
the linker (with a fully extended length of $\sim 2.5 \mathrm{~nm}$ ). Experiments with an even longer octapeptide (to be published) did not show notable difference in Fc signal, suggesting that the molecule might be folded back to the CNF surface.
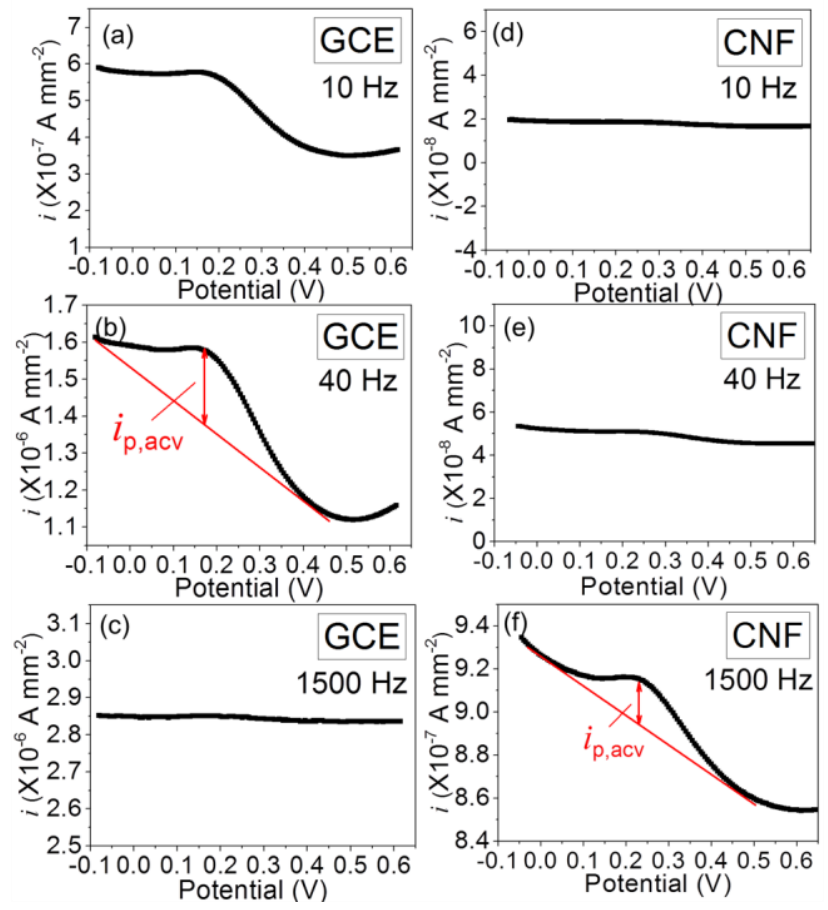

Figure 1. Comparison of AC voltammograms (ACVs) measured at 10,40 and $1500 \mathrm{~Hz}$ of $\mathrm{H}_{2} \mathrm{~N}-$ $\left(\mathrm{CH}_{2}\right)_{4}$-CO-Ala-Ala-Asn-Leu-NHCH $2-F c$ immobilized on a macro-GCE (a-c) and on a VACNF NEA (d-f). All the measurements were done in $500 \mu \mathrm{L}$ of $50 \mathrm{mM}$ MES (pH 5.0) and $250 \mathrm{mM}$ $\mathrm{NaCl}$. Sinusoidal waves with the fixed amplitude of $25 \mathrm{mV}$ were superimposed on a DC staircase ramp from -0.05 to $+0.65 \mathrm{~V}$ at a scan rate of $10 \mathrm{mV} \cdot \mathrm{s}^{-1}$. The measured average $\mathrm{AC}$ current at each point was normalized by the $7.1 \mathrm{~mm}^{2}$ geometric surface area defined by the 3-mm i.d. Oring. The actual CNF surface area is $\sim 100$ times less. 
$\mathrm{ACV}$ uses a sinusoidal $\mathrm{AC}$ voltage superimposed on a $\mathrm{DC}$ potential ramp for voltammetric measurements. It has advantages over commonly used DC-based CV, particularly for biosensors, due to the ability to amplify the electrochemical signal of small quantity of redox tags by shuffling the electron between the redox tag and the electrode many times. In general, the signal increases with $\mathrm{AC}$ frequency at low frequencies but is saturated and then decreases at higher frequencies. In our previous study using VACNF NEAs, the optimum frequency for Fc through a short $\mathrm{NH}_{2} \mathrm{CH}_{2}$ - linker was found to be 40 times higher than that on the macro-GCE. ${ }^{34}$ Figure 2 illustrates the similar phenomena with Fc attached to the electrode surface through the tetrapeptide and a longer linker group versus the AC frequency. Clearly, the optimum frequency which gave the maximum $i_{p}$ was $40 \mathrm{~Hz}$ for the GCE, but $1750 \mathrm{~Hz}$ for the VACNF NEA. Despite that both frequency values are about half of those with short $\mathrm{NH}_{2} \mathrm{CH}_{2}$ - linker, the drastic difference between VACNF NEA and macro-GCE remained the same, i.e. the optimum frequency on the VACNF NEA was $\sim 40$ times of that on the GCE. The higher applicable AC frequency at VACNF NEA afforded a larger ACV signal (i.e. $i_{p}$ ) and faster ACV measurements. Each ACV measurement in Figure 1 can be done in $\sim 60-70$ s. As a result, the kinetics of enzymatic cleavage can be monitored with continuously repeated ACV measurements at a temporal resolution of $\sim 1$ minute.

The AC peak current density $i_{\text {p,acv }}$ can be extracted by subtracting the background (as a simple sloped straight line). These values are plot in Figure 2a versus the AC frequency. Clearly, the AC peak current density of the GCE shows a sharp peak with the maximum at $40 \mathrm{~Hz}$ and a full width at half maximum (FWHM) of $\sim 140 \mathrm{~Hz}$. The current value approximately increases linearly with the $\mathrm{AC}$ frequency but drops rapidly as the AC frequency exceeds $40 \mathrm{~Hz}$. In contrast, the maximum AC peak current density was observed at $1750 \mathrm{~Hz}$ on the VACNF NEA and the FWHM asymmetrically spread over $5000 \mathrm{~Hz}$, indicating a large range of frequency that can be 
used. The current density increases about linearly with the frequency up to $\sim 1000 \mathrm{~Hz}$. When the peak current density is plot versus the logarithm of the AC frequency as shown in Figure $2 b$, the curves obtained with the GCE and the VACNF NEA show similar shape but with shifted peak frequency. It needs to be noted that the ACV measurements are not stable with the GCE. The peak shape changed significantly in about 10 minutes as shown in Figure S4, which limits the use of GCEs for the measurement of enzymatic kinetics. In contrast, the peak shape of the ACV curve of VACNF NEAs is much more stable.
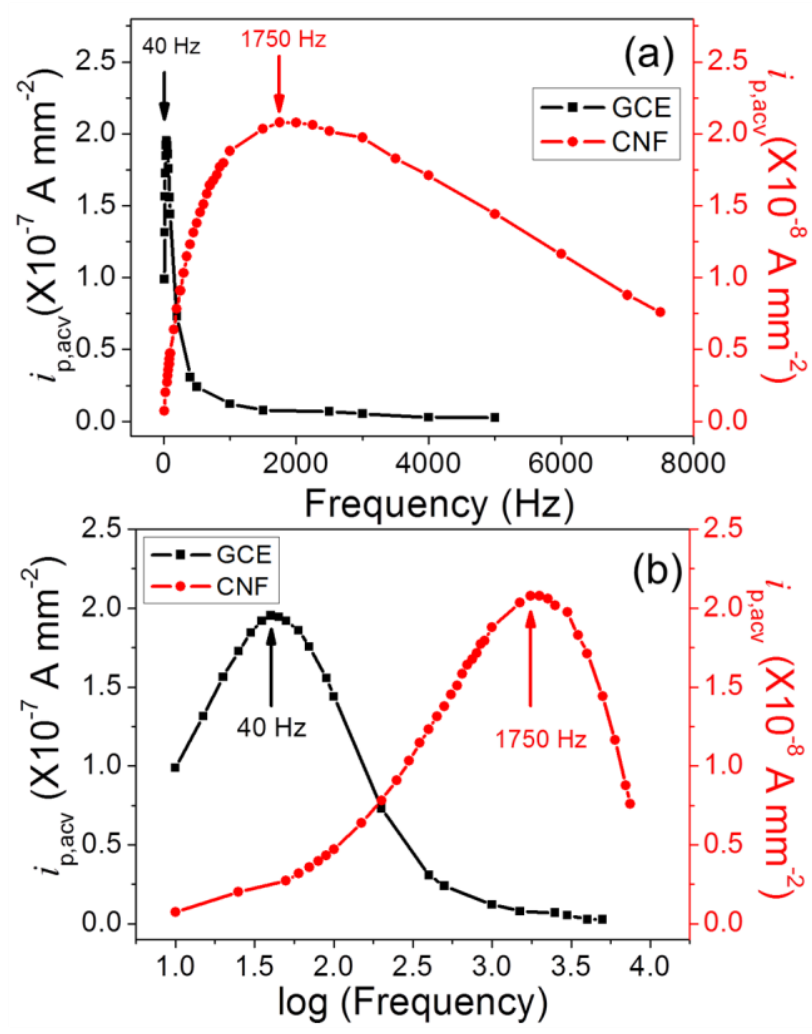

Figure 2. (a) Background-corrected ACV peak current density $i_{\text {p,acv }}$ (normalized to the $7.1 \mathrm{~mm}^{2}$ geometric electrode area) of $\mathrm{H}_{2} \mathrm{~N}-\left(\mathrm{CH}_{2}\right)_{4}$-CO-Ala-Ala-Asn-Leu- $\mathrm{NHCH}_{2}-\mathrm{Fc}$ immobilized on a GCE (square) and a VACNF NEA (filled circle) plotted against the AC frequency. (b) Plot of $i_{\mathrm{p}, \mathrm{acv}}$ versus logarithm of the AC frequency. Note: The real CNF surface area is $\sim 100$ times less than the geometric surface area defined by the O-ring. 


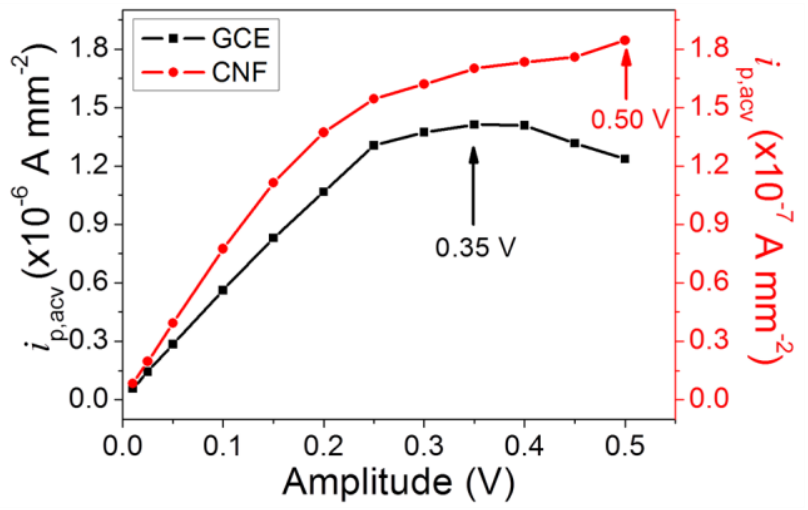

Figure 3. Background-corrected ACV peak current density $i_{\mathrm{p} \text {,acv }}$ (normalized to the $7.1 \mathrm{~mm}^{2}$ geometric electrode area) of $\mathrm{H}_{2} \mathrm{~N}-\left(\mathrm{CH}_{2}\right)_{4}$-CO-Ala-Ala-Asn-Leu- $\mathrm{NHCH}_{2}-\mathrm{Fc}$ immobilized on a GCE and a VACNF NEA plotted against the amplitude of the AC voltage (square: GCE, filled circle: VACNF NEA).

The peak current in ACVs also depended on the amplitude of the applied AC voltage. Figure 3 shows that there is a small difference between the GCE and the VACNF NEA. The peak current density $\left(i_{p, a c v}\right)$ reached to the highest value of $\sim 1.5 \times 10^{-6} \mathrm{~A} \cdot \mathrm{mm}^{-2}$ at the amplitude of $0.35 \mathrm{~V}$ for GCE while the peak current density kept increasing at the amplitude up to $0.50 \mathrm{~V}$ for VACNF NEA. However, for the VACNF NEA at amplitude larger than $0.15 \mathrm{~V}$, the value of the peak current density deviated from the linear relationship and the raw ACV peak became broad and unstable (Figure S5). For this reason, we choose amplitude at $0.15 \mathrm{~V}$ as the optimum working amplitude in all the following ACV measurements for legumain activity study. For cathepsin B study, the tetrapeptide $\mathrm{H}_{2} \mathrm{~N}-\left(\mathrm{CH}_{2}\right)_{4}-\mathrm{CO}-\mathrm{Leu}-\mathrm{Arg}-\mathrm{Phe}-\mathrm{Gly}-\mathrm{NH}-\mathrm{CH}_{2}-\mathrm{Fc}$ was immobilized on the VACNF NEA, giving very similar ACV properties with slightly different optimum AC frequency 
$(800 \mathrm{~Hz})$ and amplitude $(0.15 \mathrm{~V})$, respectively (see Figure S6). These optimum parameters were used in the following kinetic study on cathepsin B activities.
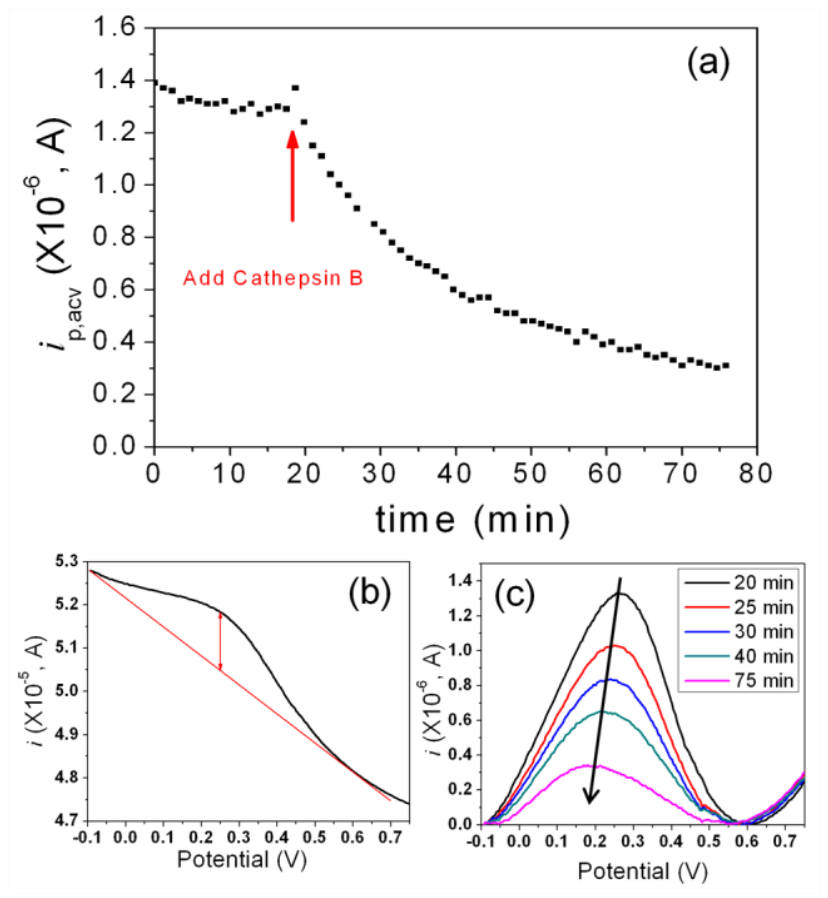

Figure 4. (a) The change of the peak current $\left(i_{p, a c v}\right)$ of $\mathrm{H}_{2} \mathrm{~N}-\left(\mathrm{CH}_{2}\right)_{4}-\mathrm{CO}-\mathrm{Leu}-\mathrm{Arg}-\mathrm{Phe}-\mathrm{Gly}-\mathrm{NH}-$ $\mathrm{CH}_{2}-\mathrm{Fc}$ immobilized on a VACNF NEA in continuously repeated ACV measurements while 25 $\mu \mathrm{L}$ of $9.8 \mathrm{ng} \cdot \mu \mathrm{L}^{-1}(338 \mathrm{nM})$ cathepsin B in the activation buffer consisting of $5 \mathrm{mM}$ DTT and 25 $\mathrm{mM}$ MES (pH 5.0) was added into the electrochemical cell containing $250 \mu \mathrm{L}$ of $25 \mathrm{mM}$ MES (pH 5.0). All ACV measurements were carried out at $f=800 \mathrm{~Hz}$ and $\mathrm{AC}$ voltage amplitude $\mathrm{V}_{0}=$ $150 \mathrm{mV}$. (b) ACV curve measured at the time of 20 minute immediately after the cathepsin B solution was added into the electrochemical cell. (c) Five representative background-subtracted ACV curves measured at 20 (black), 25 (red), 30 (blue), 40 (green) and 75 minute (pink), respectively, showing the decrease of $i_{p, a c v}$ due to enzymatic cleavage 
Figure $4 \mathrm{a}$ shows the change of peak current $\left(i_{p, a c v}\right)$ over time during continuously repeated ACV measurements with Fc-linked tetrapeptide $\left(\mathrm{H}_{2} \mathrm{~N}-\left(\mathrm{CH}_{2}\right)_{4}-\mathrm{CO}-\mathrm{Leu}-\mathrm{Arg}-\mathrm{Phe}-\mathrm{Gly}-\mathrm{NH}-\mathrm{CH}_{2}\right.$ Fc) immobilized on a VACNF NEA. The initial signal was quite stable, with only slow drifting. At $\sim 20$ minute, a solution of $25 \mu \mathrm{L}$ of $9.8 \mathrm{ng} \bullet \mu \mathrm{L}^{-1}(338 \mathrm{nM})$ cathepsin B in the activation buffer was added into the electrochemical cell, giving a final enzyme concentration of $30.7 \mathrm{nM}$. Due to the disturbance to in electrolyte, the ACV peak current jumped up and then followed by an exponential decay. Figure $4 \mathrm{~b}$ shows the ACV curve measured at 20 minute, immediately after the cathepsin B solution was added. A clear peak at around $0.25 \mathrm{~V}$ confirms the immobilization of Fc-linked tetrapeptide on the electrode surface. Figure $4 \mathrm{c}$ further illustrates the representative background-subtracted ACV curves corresponding to 0, 5, 10, 20 and 55 minutes, respectively, after adding the cathepsin B solution. The peak current clearly decreased over time and the peak position slowly shifted from $0.27 \mathrm{~V}$ to $0.18 \mathrm{~V}$. Two control experiments (Figure S7) were carried out and confirmed that the exponential decay in $i_{\mathrm{p} \text {,acv }}$ was truly attributed to the kinetics of enzymatic cleavage of the peptide. First, $25 \mu \mathrm{L}$ of blank activation buffer, i.e. $5 \mathrm{mM}$ DTT and 25 mM MES ( $\mathrm{pH} 5.0$ ), was added into the electrochemical cell prefilled with $250 \mu \mathrm{L}$ of electrolyte (25 mM MES ( $\mathrm{pH}$ 5.0)). The disturbance to the ACV signal was negligible in this process. Second, a solution of $25 \mu \mathrm{L}$ of activation buffer containing deactivated cathepsin B (which was confirmed with the fluorescence assay) was added into the electrochemical cell in the similar way as in the first case. Neither case showed the characteristic exponential decay observed when the activated enzyme was introduced. It is clear that the exponential decay was due to enzymatic cleavage to the tetrapeptide substrate by cathepsin B.

The observed proteolysis kinetics may be explained with a modified Michaelis-Menten model for heterogeneous enzymatic reactions: ${ }^{37}$ 


$$
\mathrm{E}+\mathrm{S}_{\mathrm{s}} \underset{k_{-1}}{\stackrel{k_{1}}{\longrightarrow}} \mathrm{ES}_{\mathrm{s}} \stackrel{k_{c a t}}{\longrightarrow} \mathrm{E}+\mathrm{P}_{\mathrm{s}}+\mathrm{P},
$$

where $\mathrm{E}, \mathrm{S}_{\mathrm{s}}, \mathrm{ES}_{\mathrm{s}}, \mathrm{P}_{\mathrm{s}}$ and $\mathrm{P}$ represent the enzyme, the surface-bound peptide substrate, the enzyme-substrate complex on the electrode surface, the surface-attached product, and the product released to solution, respectively. The reaction rate can be defined as

$$
v=-\frac{d \Gamma_{S_{s}}}{d t}=\frac{d \Gamma_{P_{s}}}{d t}=\frac{k_{c a t}\left[\mathrm{E}_{0}\right] \times \Gamma_{S_{s}}}{\mathrm{~K}_{\mathrm{m}}+\left[\mathrm{E}_{0}\right]},
$$

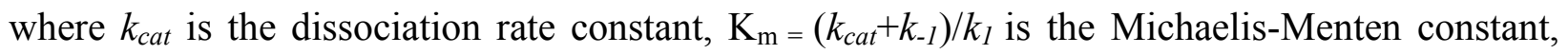
and $\Gamma_{\mathrm{Ss}}$ and $\Gamma_{\mathrm{Ps}}$ represent the surface densities of original and reacted peptide substrates, respectively. At low enzyme concentrations with $\left[\mathrm{E}_{0}\right]<<\mathrm{K}_{\mathrm{m}}$, an approximate relationship can be obtained as

$$
v=-\frac{d \Gamma_{s}}{d t}=\frac{d \Gamma_{P_{s}}}{d t}=\frac{k_{c a t}}{\mathrm{~K}_{\mathrm{m}}}\left[\mathrm{E}_{0}\right] \times \Gamma s_{s} .
$$

The reaction rate $v$ (or $\left.-d \Gamma_{S s} / d t\right)$ is a time-dependent quantity proportional to the change in electrochemical signals $(d S / d t)$, where $S$ is the kinetic electrochemical signal corresponding to the peak current $i_{p}$ in ACV measurements. As a result the slope of $(d S / d t)$ versus the time-dependent $\Gamma_{S s}$ will be equal to $\left(k_{c a t} / \mathrm{K}_{\mathrm{m}}\right)\left[\mathrm{E}_{0}\right]$, namely

$$
-\frac{d \Gamma S_{s} / d t}{\Gamma_{S_{s}}}=-\frac{d S / d t}{S}=\frac{k_{c a t}}{\mathrm{~K}_{\mathrm{m}}}\left[\mathrm{E}_{0}\right] .
$$

Thus, by rearranging the kinetic electrochemical data, we can derive the value of "specificity constant" $k_{\text {cat }} / \mathrm{K}_{\mathrm{m}}$ which is commonly used to represent the catalytic efficiency of enzymes. 

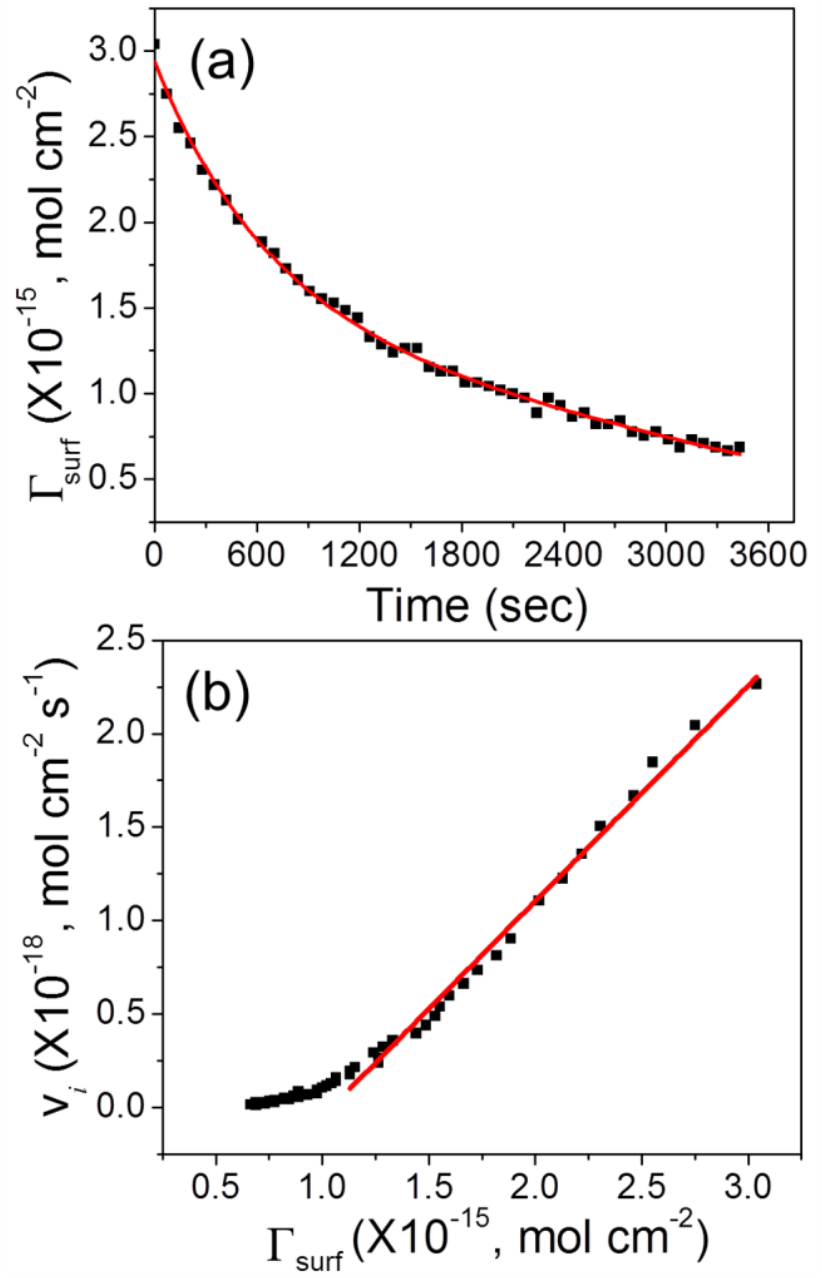

Figure 5. Replot of the data presented in Figure 4. (a) Decrease of the quantity of surface adsorbed Fc (i.e. $\Gamma_{\text {surf }}$ ) during enzymatic cleavage of the tetrapeptide after adding the cathepsin B solution. (b) Plot of the reaction rate $\left(v_{\mathrm{i}}\right)$ versus the quantity of surface adsorbed $\mathrm{Fc}\left(\Gamma_{\text {surf }}\right)$ during the enzymatic reaction.

To further analyze the kinetic enzymatic process, the peak current in ACV was converted into the quantity of surface adsorbed Fc (i.e. $\Gamma_{\text {surf }}$ ) based on ${ }^{38}$

$$
i_{p, a c v}=\left(\frac{2}{\pi}\right)\left(\frac{F^{2}}{4 R T}\right) \Gamma_{\text {surf }}(2 \pi f) V_{0}
$$


where the AC frequency $f$ was $800 \mathrm{~Hz}$ and the amplitude of the AC voltage $V_{0}$ was $150 \mathrm{mV}$. Although the $\Gamma_{\text {surf }}$ value derived with Equation 5 is known to be smaller than that obtained with other methods, particularly at high frequencies, the linear relationship between $i_{p, a c v}$ and $\Gamma_{\text {surf }}$ remains true. The deviation of the proportional coefficient from the true value iscancelled in later steps and does not affect the final results. As shown in Figure 5a, the kinetic data can be fitted with an exponential decay superimposed on a linear curve corresponding to the slow baseline drift. The fitting equation is

$$
\Gamma_{\text {surf }}=1.55 \times 10^{-15} \times e^{\left(-\frac{t}{683.6}\right)}-2.19 \times 10^{-19} t+1.38 \times 10^{-15}
$$

From equation 6 , the reaction rate $v_{i}$ at different $\Gamma_{\text {surf }}$ can be calculated. The results were presented in Figure $5 \mathrm{~b}$, which appeared to be a linear curve in the high $\Gamma_{\text {surf }}$ region. This linear curve is fitted by equation

$$
v_{i}=1.15 \times 10^{-3} \Gamma_{\text {surf }}-1.20 \times 10^{-18} .
$$

As mentioned earlier, both $v_{i}$ and $\Gamma_{\text {surf }}$ are proportional to $i_{p, a c v}$. The slope of $v_{i}$ versus $\Gamma_{\text {surf }}$, however, is independent of the exact proportional coefficient since it presented in both $v_{i}$ and $\Gamma_{\text {surf }}$ and is thus cancelled. Therefore, we can derive the exact slope without being affected by the ACV experimental conditions. Equation 7 gives a slope of $1.15 \times 10^{-3} \mathrm{~s}^{-1}$, which equals to $\left(k_{c a t} / \mathrm{K}_{\mathrm{m}}\right)\left[\mathrm{E}_{0}\right]$ as described in Equation 3. With $\left[\mathrm{E}_{0}\right]=30.7 \mathrm{nM}$, the value of the "specificity constant" $k_{\text {cat }} / \mathrm{K}_{\mathrm{m}}$ can be calculated as $3.8 \times 10^{4} \mathrm{M}^{-1} \mathrm{~s}^{-1}$. This value is close to the value of $2.3 \mathrm{x}$ $10^{4} \mathrm{M}^{-1} \mathrm{~s}^{-1}$ derived from the comprehensive analysis with the fluorescence assay in a series of peptide substrate concentrations (Figures S8 and S9). It is also within the range reported in literature which varies from $\sim 2 \times 10^{3} \mathrm{M}^{-1} \mathrm{~s}^{-1}$ to $\sim 7 \times 10^{6} \mathrm{M}^{-1} \mathrm{~s}^{-1}$. $37,39-40$ 

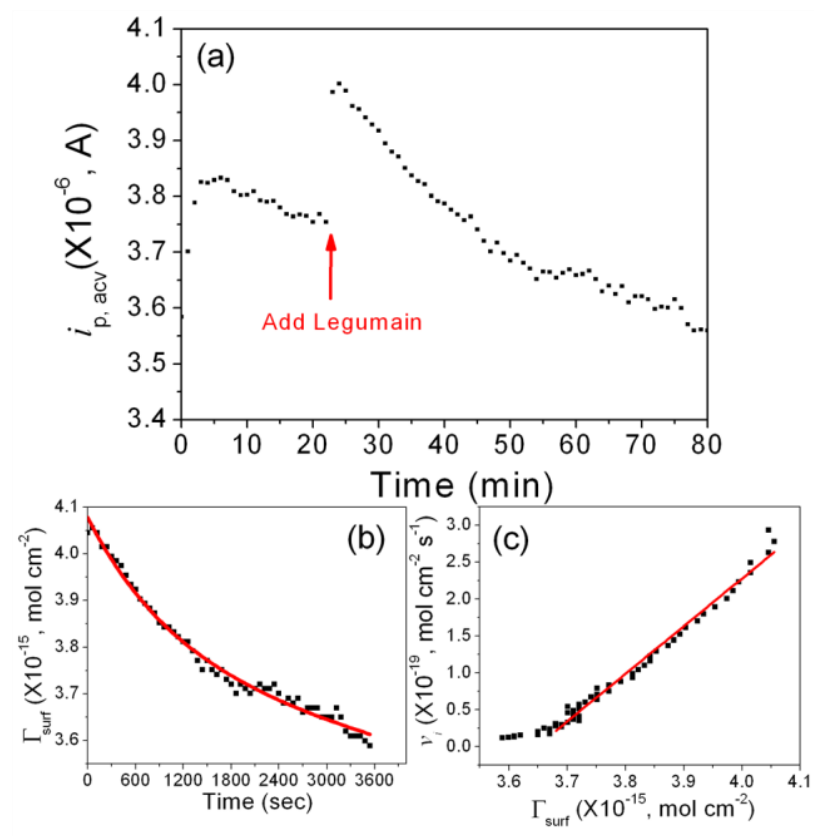

Figure 6. (a) The change of the peak current $\left(i_{p, a c v}\right)$ of $\mathrm{H}_{2} \mathrm{~N}-\left(\mathrm{CH}_{2}\right)_{4}-\mathrm{CO}-\mathrm{Ala}-\mathrm{Ala}-\mathrm{Asn}-\mathrm{Leu}-\mathrm{NH}-$ $\mathrm{CH}_{2}$-Fc immobilized on a VACNF NEA in continuously repeated ACV measurements while 11 $\mu \mathrm{L}$ of $90.9 \mathrm{ng} \mu \mathrm{L}^{-1}(1.90 \mu \mathrm{M})$ legumain in the activation buffer consisting of $50 \mathrm{mM} \mathrm{CH}_{3} \mathrm{COONa}$ $(\mathrm{pH}=4.0$, adjusted by adding acetic acid) and $100 \mathrm{mM} \mathrm{NaCl}$ was added into the electrochemical cell containing $250 \mu \mathrm{L}$ of $50 \mathrm{mM}$ MES (pH 5.0) and $250 \mathrm{mM} \mathrm{NaCl}$. All ACV measurements were carried out at $f=1750 \mathrm{~Hz}$ and $\mathrm{AC}$ voltage amplitude $\mathrm{V}_{0}=150 \mathrm{mV}$. (b) Replot of the data presented in figure (a) showing the reduction of the quantity of surface adsorbed Fc (i.e. $\Gamma_{\text {surf }}$ ) during enzymatic cleavage of the tetrapeptide after adding the legumain. (c) Plot of the reaction rate $\left(v_{\mathrm{i}}\right)$ versus the quantity of surface adsorbed $\mathrm{Fc}\left(\Gamma_{\text {surf }}\right)$ during the enzymatic reaction.

Figure 6 shows the ACV measurements with $\mathrm{H}_{2} \mathrm{~N}-\left(\mathrm{CH}_{2}\right)_{4}-\mathrm{CO}-\mathrm{Ala}-\mathrm{Ala}-\mathrm{Asn}-\mathrm{Leu}-\mathrm{NH}-\mathrm{CH}_{2}-\mathrm{Fc}$ immobilized on a VACNF NEA. Comparing to cathepsin B, the change of peak current corresponding to the cleavage by legumain was smaller, likely due to the difference in the enzyme activity. None of the two control experiments in Figure S10 by adding the blank 
activation buffer and the buffer containing deactivated legumain (confirmed with fluorescence assay), respectively, showed the characteristic exponential decay in $i_{p, a c v}$. The former caused negligible disturbance to the electrochemical signal. The latter caused the $i_{p, a c v}$ to slowly rise by $\sim 5 \%$ after 5 minutes and then became stabilized, which might be attributed to the disturbance to the tetrapeptide conformation on the electrode surface.

The data in Figure $6 \mathrm{~b}$ can be fitted with the following equation:

$$
\Gamma_{\text {surf }}=3.23 \times 10^{-16} \times e^{\left(-\frac{t}{1101}\right)}-4.36 \times 10^{-20} t+3.75 \times 10^{-15}
$$

where the time constant is $1101 \mathrm{~s}(\sim 18 \mathrm{~min}$.), indicating that the reaction is quite slow. It normally took $\sim 1$ hour to complete the kinetic measurement. This was found to be limited by the low enzymatic activity of legumain. However, it was still possible to extract the faradaic signal of $\mathrm{Fc}$ from the varying background with the $\mathrm{ACV}$ measurements. Figure $6 \mathrm{c}$ gives a linear curve fitted by equation $v_{i}=6.30 \times 10^{-4} \Gamma_{\text {surf }}-2.30 \times 10^{-18}$ with the slope of $6.30 \times 10^{-4} \mathrm{~s}^{-1}$ at $\left[\mathrm{E}_{0}\right]=80.1$ $\mathrm{nM}$. From this analysis, the value of the $k_{\text {cat }} / \mathrm{K}_{\mathrm{m}}$ can be calculated as $7.9 \times 10^{3} \mathrm{M}^{-1} \mathrm{~s}^{-1}$. This value is higher than the value of $4.3 \times 10^{3} \mathrm{M}^{-1} \mathrm{~s}^{-1}$ derived from the comprehensive analysis using the fluorescence assay (Figures S11 and S12) and the specifications provided by the vendor (R\&D Systems).

The kinetic measurements with ACV for both cathepsin B and legumain were repeated at least three times under similar conditions as those in Figure 4 and Figure 6. The results were consistent and reproducible. More comprehensive measurements at varied enzyme concentrations and peptide lengths will be reported in future studies. Table 1 summarizes the statistical values of the specificity constant $k_{c a t} / \mathrm{K}_{\mathrm{m}}$ derived from both electrochemical method using ACVs on VACNF NEAs in comparison with the fluorescence assay based on a series of substrate 
concentrations in solution, for both legumain and cathepsin B. Interestingly, the electrochemical method gave higher $k_{c a t} / \mathrm{K}_{\mathrm{m}}$ values for both of legumain and cathepsin B than the fluorescence assay. In contrast, other studies using macroscopic electrodes found that the electrochemically measured $k_{\text {cat }} / \mathrm{K}_{\mathrm{m}}$ was normally lower than solution based assays, primarily due to the steric effects which lower the access of enzyme to the peptides attached to the flat surface. ${ }^{15-16}$ The results confirmed that the small radius in VACNF NEAs helped to eliminate the steric hindrance. The peptide substrates for the fluorescence assay consisted of only 3 and 2 amino acids, respectively, which were also expected to have lower binding affinity than the tetrapeptides used for our electrochemical measurements.

Table 1. Comparison of the specificity constant $k_{\text {cat }} / \mathrm{K}_{\mathrm{m}}$ for legumain and cathepsin B, derived from the electrochemical method (i.e. ACV on VACNF NEAs) and the fluorescence assay in solutions.

\begin{tabular}{|l|l|l|}
\hline Enzyme & Peptide Sequence & $\boldsymbol{k}_{\text {cat }} / \mathbf{K}_{\mathbf{m}}\left(\mathbf{M}^{-1} \mathbf{s}^{-1}\right)$ \\
\hline \multirow{2}{*}{ Legumain } & $\left(\mathrm{FL}^{\text {a }}\right)$ Ala-Ala-Asn-AMC & $(4.3 \pm 0.6) \times 10^{3}$ \\
\cline { 2 - 3 } & $\left(\mathrm{EC}^{\mathrm{b}}\right)$ Ala-Ala-Asn-Leu-NH-CH 2 -Fc & $(11.3 \pm 3.8) \times 10^{3}$ \\
\hline \multirow{2}{*}{ Cathepsin B } & (FL) Leu-Arg-AMC & $(2.3 \pm 1.7) \times 10^{4}$ \\
\cline { 2 - 3 } & (EC) Leu-Arg $\downarrow$ Phe-Gly-NH-CH 2 -Fc & $(4.3 \pm 0.8) \times 10^{4}$ \\
\hline
\end{tabular}

${ }^{a}$ FL: fluorescence; $\downarrow$ : cleavage site. The fluorescence data were derived from the analysis in Figures S8, S9, S11 and S12.

${ }^{b}$ EC: electrochemistry. The electrochemical data were statistical value over at least duplicated experiments.

The values of the specificity constant $k_{\text {cat }} / \mathrm{K}_{\mathrm{m}}$ for cathepsin B by both electrochemical and fluorescence assays are about 5 times of that of legumain. For ACV measurements, this helps to 
reduce the time constant for the exponential decay and makes the experiment easier and more reliable. As a result, lower enzyme concentration can be measured. From these results, it can be concluded that the ACV would work even better for measuring proteases with the $k_{\text {cat }} / \mathrm{K}_{\mathrm{m}}$ values higher than $\sim 4 \times 10^{4} \mathrm{M}^{-1} \mathrm{~s}^{-1}$. But even proteases with relatively low specificity constant (such as legumain and cathepsin B) can still be reliably measured. Even though the required enzyme concentration was $\sim 5$ to 10 times higher than that by the fluorescence assay, the electrochemical method has a potential advantage that simultaneous detection of multiple proteases in a small volume is possible, attributed to its localized sensing mechanism using surface-attached peptides. Further investigation is in progress to assess the cross-reactions between different enzymesubstrate pairs.

The vendor suggests that legumain cleaves peptide bonds with asparagine (Asn) at the P1 position while it has been reported that cathepsin B cleaves peptide or AMC bonds with arginine (Arg) at P1 site. ${ }^{41}$ To confirm the cleavage site, we have incubated each tetrapeptide with legumain and cathepsin B and measured the products with HPLC. As shown in Figure S13 and Figure S14, the HPLC graphs of the cleaved products were directly compared with those of the pure tetrapeptides and synthesized fragments (mono amino acid or dipeptide). The cleaved products were further validated with mass spectrometry. These experiments clearly demonstrated the cleavage site as listed in Table 1. Interestingly, even after incubating for 2 hours, the cleaved tetrapepetide concentration was only $\sim 1 / 5$ of the total concentration for legumain and $\sim 3 / 4$ for cathepsin B. The fluorescence assay reported earlier is sensitive to the absolute amount of cleaved products while the electrochemical assay is sensitive to the percentage of the cleavage to the surface-attached peptide. The large amount of starting peptides used in the fluorescence assay partially contributed to its capability to measure lower enzyme concentrations. The 
electrochemical method, however, has advantage for miniaturization and multiplexing which may be critical for rapidly screening multiple proteases in disease diagnosis. It is noteworthy that the $k_{\text {cat }} / \mathrm{K}_{\mathrm{m}}$ values of legumain and cathepsin B are relatively low, but they have high biological significance respect to cancer diagnosis and treatment. The speed and required enzyme concentration in the electrochemical measurements can be significantly improved when this technique is used to detect other proteases with higher $k_{\text {cat }} / \mathrm{K}_{\mathrm{m}}$ values, such as trypsin at $(1.44$ $\pm 0.1) \times 10^{6} \mathrm{M}^{-1} \mathrm{~s}^{-1},{ }^{15} \alpha$-thrombin at $(1.0 \pm 0.2) \times 10^{6} \mathrm{M}^{-1} \mathrm{~s}^{-1},{ }^{15}$ and plasmin at $6.7 \times 10^{5} \mathrm{M}^{-1} \mathrm{~s}^{-1} .{ }^{16}$

In previous electrochemical detection of proteases including trypsin, ${ }^{15}$ a-thrombin, ${ }^{15}$ and plasmin, ${ }^{16}$ normal CV measurements on gold electrodes were used. This method was found not applicable on carbon electrode. As shown in Figure S15, the Fc redox waves of the labeled tetrapeptide can be observed on the GCE, but the baseline currents were quite high, making it difficult to reliably extract redox signals. The previous studies on gold electrodes were able to block the nonfaradaic background current using close-packed self-assembled monolayer of small passivating alkane thiol molecules. The covalent bond of small passivating molecules does not allow them to move around to form a close-packed monolayer. Thus there were many leaking pinholes in the passivation layer on GCE. This is even more severe on VACNF NEA due to the curvature and inhomogeneity at the CNF surface. As a result, it was not possible to use $\mathrm{CV}$ to measure the Fc signal on VACNF NEAs. ACV provides a necessary solution for the reported enzymatic study.

While we have demonstrated that it is feasible to detect the enzymatic kinetics of both legumain and cathepsin B. It remains critical to evaluate the specificity for any practical applications. This will be carefully investigated in the future. Our preliminary data indicated that the specificity of protease detection using this reported method strongly depended on the value of the "specificity constant" $k_{c a t} / \mathrm{K}_{\mathrm{M}}$. Cathepsin B has higher $k_{c a t} / \mathrm{K}_{\mathrm{M}}$ which resulted in $\sim 75 \%$ of drop 
in the electrochemical signal due to cleavage to the designated tetrapeptide (see Figure 4). As a result, the exponential decay can be reliably measured, giving high specificity. In contrast, as shown in Figure S16, the change of electrochemical signal is negligible using a tetrapeptide without Arg. For legumain, the low value of $k_{c a t} / \mathrm{K}_{\mathrm{M}}$ caused that the electrochemical signal only dropped by $\sim 10 \%$ (see Figure $6 \mathrm{a}$ ). The disturbance to the electrode during adding the enzyme solution caused uncontrollable fluctuation in the electrochemical signal. This limited precisely deriving the $k_{c a t} / \mathrm{K}_{\mathrm{M}}$ value. Therefore, the specificity for legumain is inconclusive at this stage and needs careful further study. But we can conclude that $k_{c a} / \mathrm{K}_{\mathrm{M}}$ of $(1.13 \pm 0.38) \times 10^{4} \mathrm{M}^{-1} \mathrm{~s}^{-1}$ (as for legumain) is about the low limit for reliable protease measurements using the current setup.

\section{Conclusions}

In summary, we have demonstrated that high-frequency ACV can be applied on embedded VACNF NEAs to measure the redox reaction of $\mathrm{Fc}$ attached to the exposed CNF tip through a tetrapeptide and linker molecule. Due to the additional capacitive current pathway enabled by the unique interior graphitic microstructure of the VACNFs, the optimum frequency giving the highest peak AC current for Fc on VACNF NEA was found to be 40 times of that on GCEs. The higher frequency afforded a larger ACV signal and shorter time for the each ACV measurements. Thus the kinetics of proteolysis of the surface-attached peptides can be measured upon addition of two types of cancer related proteases, i.e. legumain and cathepsin B. The kinetic process can be analyzed with a heterogeneous Michaelis-Menten model to derive the "specificity constant" $k_{\text {cat }} / \mathrm{K}_{\mathrm{m}}$, which is $(4.3 \pm 0.8) \times 10^{4} \mathrm{M}^{-1} \mathrm{~s}^{-1}$ for cathepsin $\mathrm{B}$ and $(1.13 \pm 0.38) \times 10^{4} \mathrm{M}^{-1} \mathrm{~s}^{-1}$ for legumain. These values are about 2 times of that measured with a fluorescence assay as well as the specifications provided by the vendor. The nanostructured electrode size clearly eliminated 
the steric effects for enzymatic reactions with surface-attached peptides. This is the first example of the use of VACNF NEA on protease activity study. These VACNF NEA based electrochemical enzymatic biosensors can be potentially developed into portable multiplex electronic devices for rapid cancer diagnosis and treatment monitoring. Further study on the specificity and sensitivity of this VACNF NEA biosensor applied with biological samples is in progress toward this goal.

\section{AUTHOR INFORMATION}

\section{Corresponding Author}

*E-mail: junli@ksu.edu.

\section{Author Contributions}

The manuscript was written through contributions of all authors. All authors have given approval to the final version of the manuscript.

\section{Acknowledgment}

This work was supported by Award Number R15CA159250 from the National Cancer Institute, and, in part, by grant number P20RR015563 from the National Center for Research Resources and by Johnson Center for Basic Cancer Research at Kansas State University. The content of this article is solely the responsibility of the authors and does not necessarily represent the official views of the NCI or the NIH.

Supporting Information Available. FESEM image of VACNF NEA. Schemes for the syntheses of $\mathrm{H}_{2} \mathrm{~N}-\left(\mathrm{CH}_{2}\right)_{4} \mathrm{CO}$-Ala-Ala-Asn-Leu- $\mathrm{NHCH}_{2}-\mathrm{Fc}$ for legumain and $\mathrm{H}_{2} \mathrm{~N}-\left(\mathrm{CH}_{2}\right)_{4}-\mathrm{CO}-$ 
Leu-Arg-Phe-Gly-NH-CH$-\mathrm{CH}_{2}-\mathrm{Fc}$ for cathepsin B. The stability test of ACV of Fc-linked tetrapeptide attached on a macroscopic GCE. ACVs of cathepsin B tetrapeptide substrate $\mathrm{H}_{2} \mathrm{~N}-$ $\left(\mathrm{CH}_{2}\right)_{4}$-CO-Ala-Ala-Asn-Leu-NH-CH $2-\mathrm{Fc}$ immobilized on a macroscopic GCE and a VACNF NEA at different amplitudes of AC voltage. ACV peak current density $i_{p, a c v}$ of cathepsin B tetrapeptide substrate $\mathrm{H}_{2} \mathrm{~N}-\left(\mathrm{CH}_{2}\right)_{4}-\mathrm{CO}-\mathrm{Leu}-\mathrm{Arg}-\mathrm{Phe}-\mathrm{Gly}-\mathrm{NH}-\mathrm{CH}_{2}-\mathrm{Fc}$ immobilized on a VACNF NEA plotted against logarithm of the frequency and the amplitude of AC voltage. Negative control electrochemical experiments of cathepsin B study. Kinetic measurements and analyses of cathepsin B activity using the fluorescence assay. Negative control electrochemical experiments of legumain study. Kinetic measurements and analyses of legumain activity using the fluorescence assay. HPLC analyses of cathepsin B and legumain cleavage sites. Cyclic voltammetry of Fc-tetrapeptide functionalized on a GCE and a VACNF NEA. Specificity testing result of cathepsin B. This information is available free of charge via the Internet at http://pubs.acs.org.

\section{References}

(1) Carmeliet, P., Angiogenesis in Health and Disease. Nat. Med. 2003, 9, 653-660.

(2) Koblinski, J. E.; Ahram, M.; Sloane, B. F., Unraveling the Role of Proteases in Cancer. Clin. Chim. Acta 2000, 291, 113-135.

(3) Puente, X. S.; Sanchez, L. M.; Overall, C. M.; Lopez-Otin, C., Human and Mouse Proteases: a Comparative Genomic Approach. Nat. Rev. Genet. 2003, 4, 544-558.

(4) Murthy, R. V.; Arbman, G.; Gao, J.; Roodman, G. D.; Sun, X., Legumain Expression in Relation to Clinicopathologic and Biological Variables in Colorectal Cancer. Clin. Cancer Res. 2005, 11, 2293-2299.

(5) Shirahama-Noda, K.; Yamamoto, A.; Sugihara, K.; Hashimoto, N.; Asano, M.; Nishimura, M.; Hara-Nishimura, I., Biosynthetic Processing of Cathepsins and Lysosomal Degradation are Abolished in Asparaginyl Endopeptidase-Deficient Mice. J. Biol. Chem. 2003, 278, 3319433199.

(6) Mattock, K. L.; Gough, P. J.; Humphries, J.; Burnand, K.; Patel, L.; Suckling, K. E.; Cuello, F.; Watts, C.; Gautel, M.; Avkiran, M., et al., Legumain and Cathepsin-L Expression in Human Unstable Carotid Plaque. Atherosclerosis 2010, 208, 83-89. 
(7) Gawenda, J.; Traub, F.; Lück, H.; Kreipe, H.; von Wasielewski, R., Legumain Expression as a Prognostic Factor in Breast Cancer Patients. Breast Cancer Res. Treat. 2007, 102, 1-6.

(8) Briggs, J.; Haugen, M.; Johansen, H.; Riker, A.; Abrahamson, M.; Fodstad, O.; Maelandsmo, G.; Solberg, R., Cystatin E/M Suppresses Legumain Activity and Invasion of Human Melanoma. BMC Cancer 2010, 10, 17.

(9) Turk, B., Targeting Proteases: Successes, Failures and Future Prospects. Nat. Rev. Drug Discov. 2006, 5, 785-799.

(10) Tang, Z.; Wu, H.; Zhang, Y.; Li, Z.; Lin, Y., Enzyme-Mimic Activity of Ferric Nano-Core Residing in Ferritin and Its Biosensing Applications. Analytical Chemistry 2011, 83, 8611-8616. (11) Shimura, K.; Kasai, K.; Matsumoto, H., Assay of Trypsin Activity by Capillary Isoelectric Focusing with Laser-Induced Fluorescence Detection. Electrophoresis 1998, 19, 2296-2300.

(12) Vestling, M. M.; Murphy, C. M.; Fenselau, C., Recognition of Trypsin Autolysis Products by High-Performance Liquid Chromatography and Mass Spectrometry. Anal. Chem. 1990, 62, 2391-2394.

(13) Orosco, M. M.; Pacholski, C.; Miskelly, G. M.; Sailor, M. J., Protein-Coated PorousSilicon Photonic Crystals for Amplified Optical Detection of Protease Activity. Adv. Mater. 2006, 18, 1393-1396.

(14) Hook, V. Y.; Schiller, M. R. ; Nguye, C. ; Yasothornsrikul, S. , Production of Radiolabeled Neuropeptide Precursors by in Vitro Transcription and Translation. Pept. Res. 1996, 9, 183-187.

(15) Adjemian, J.; Anne, A.; Cauet, G.; Demaille, C., Cleavage-Sensing Redox Peptide Monolayers for the Rapid Measurement of the Proteolytic Activity of Trypsin and $\alpha$-Thrombin Enzymes. Langmuir 2010, 26, 10347-10356.

(16) Ohtsuka, K.; Maekawa, I.; Waki, M.; Takenaka, S., Electrochemical Assay of Plasmin Activity and Its Kinetic Analysis. Anal. Biochem. 2009, 385, 293-299.

(17) Penner, R. M.; Heben, M. J.; Longin, T. L.; Lewis, N. S., Fabrication and Use of Nanometer-Sized Electrodes in Electrochemistry. Science 1990, 250, 1118-1121.

(18) Fan, F. R.; Bard, A. J., Electrochemical Detection of Single Molecules. Science 1995, 267, 871-874.

(19) Menon, V. P.; Martin, C. R., Fabrication and Evaluation of Nanoelectrode Ensembles. Anal. Chem. 1995, 67, 1920-1928.

(20) Wei, D.; Bailey, M. J. A.; Andrew, P.; Ryhanen, T., Electrochemical Biosensors at The Nanoscale. Lab Chip 2009, 9, 2123-2131.

(21) Lapierre-Devlin, M. A.; Asher, C. L.; Taft, B. J.; Gasparac, R.; Roberts, M. A.; Kelley, S. O., Amplified Electrocatalysis at DNA-Modified Nanowires. Nano Lett. 2005, 5, 1051-1055. (22) Lanyon, Y. H.; De Marzi, G.; Watson, Y. E.; Quinn, A. J.; Gleeson, J. P.; Redmond, G.; Arrigan, D. W. M., Fabrication of Nanopore Array Electrodes by Focused Ion Beam Milling. Anal. Chem. 2007, 79, 3048-3055.

(23) Li, H.; Wu, N., A Large-Area Nanoscale Gold Hemisphere Pattern as a Nanoelectrode Array. Nanotechnology 2008, 19, 275301.

(24) Li, J.; Koehne, J. E.; Cassell, A. M.; Chen, H.; Ng, H. T.; Ye, Q.; Fan, W.; Han, J.; Meyyappan, M., Inlaid Multi-Walled Carbon Nanotube Nanoelectrode Arrays for Electroanalysis. Electroanalysis 2005, 17, 15-27.

(25) Lin, Y.; Lu, F.; Tu, Y.; Ren, Z., Glucose Biosensors Based On Carbon Nanotube Nanoelectrode Ensembles. Nano Lett. 2004, 4, 191-195. 
(26) Baker, S. E.; Tse, K. Y.; Lee, C. S.; Hamers, R. J., Fabrication and Characterization of Vertically Aligned Carbon Nanofiber Electrodes for Biosensing Applications. Diamond Relat. Mater. 2006, 15, 433-439.

(27) Arumugam, P. U.; Chen, H.; Siddiqui, S.; Weinrich, J. A. P.; Jejelowo, A.; Li, J.; Meyyappan, M., Wafer-scale Fabrication of Patterned Carbon Nanofiber Nanoelectrode Arrays: a Route for Development of Multiplexed, Ultrasensitive Disposable Biosensors. Biosens. Bioelectron. 2009, 24, 2818-2824.

(28) Li, J.; Ng, H. T.; Cassell, A.; Fan, W.; Chen, H.; Ye, Q.; Koehne, J.; Han, J.; Meyyappan, M., Carbon Nanotube Nanoelectrode Array for Ultrasensitive DNA Detection. Nano Lett. 2003, 3, 597-602.

(29) Koehne, J. E.; Marsh, M.; Boakye, A.; Douglas, B.; Kim, I. Y.; Chang, S.-Y.; Jang, D.-P.; Bennet, K. E.; Kimble, C.; Andrews, R., et al., Carbon Nanofiber Electrode Array for Electrochemical Detection of Dopamine Using Fast Scan Cyclic Voltammetry. Analyst 2010, 136, 1802-1805.

(30) Yu, Z.; McKnight, T. E.; Ericson, M. N.; Melechko, A. V.; Simpson, M. L.; Morrison, B., Vertically Aligned Carbon Nanofiber Arrays Record Electrophysiological Signals From Hippocampal Slices. Nano Lett. 2007, 7, 2188-2195.

(31) McKnight, T. E.; Melechko, A. V.; Hensley, D. K.; Mann, D. G. J.; Griffin, G. D.; Simpson, M. L., Tracking Gene Expression After DNA Delivery Using Spatially Indexed Nanofiber Arrays. Nano Lett. 2004, 4, 1213-1219.

(32) Koehne, J.; Li, J.; Cassell, A. M.; Chen, H.; Ye, Q.; Ng, H. T.; Han, J.; Meyyappan, M., The Fabrication and Electrochemical Characterization of Carbon Nanotube Nanoelectrode Arrays. J. Mater. Chem. 2004, 14, 676-684.

(33) Banks, C. E.; Davies, T. J.; Wildgoose, G. G.; Compton, R. G., Electrocatalysis at Graphite and Carbon Nanotube Modified Electrodes: Edge-Plane sites and Tube Ends are the Reactive Sites. Chem. Commun. 2005, 2005, 829-841.

(34) Syed, L. U.; Liu, J.; Prior, A. M.; Hua, D. H.; Li, J., Enhanced Electron Transfer Rates by AC Voltammetry for Ferrocenes Attached to the End of Embedded Carbon Nanofiber Nanoelectrode Arrays. Electroanalysis 2011, 23, 1709-1717.

(35) Beer, P. D.; Smith, D. K., Tunable Bis(ferrocenyl) Receptors for the Solution-Phase Electrochemical Sensing of Transition-Metal Cations. J. Chem. Soc., Dalton Trans. 1988, 417. (36) Li, J.; Ng, H. T.; Cassell, A.; Fan, W.; Chen, H.; Ye, Q.; Koehne, J.; Han, J.; Meyyappan, M., Carbon Nanotube Nanoelectrode Array for Ultrasensitive DNA Detection. Nano Letters 2003, 3, 597-602.

(37) Gutiérrez, O. A.; Chavez, M.; Lissi, E., A Theoretical Approach to Some Analytical Properties of Heterogeneous Enzymatic Assays. Anal. Chem. 2004, 76, 2664-2668.

(38) Creager, S.; Yu, C. J.; Bamdad, C.; O'Connor, S.; MacLean, T.; Lam, E.; Chong, Y.; Olsen, G. T.; Luo, J.; Gozin, M., et al., Electron Transfer at Electrodes Through Conjugated "Molecular Wire" Bridges. J. Am. Chem. Soc. 1999, 121, 1059-1064.

(39) Almeida, P. C.; Oliveira, V.; Chagas, J. R.; Meldal, M.; Juliano, M. A.; Juliano, L., Hydrolysis by Cathepsin B of Fluorescent Peptides Derived From Human Prorenin. Hypertension 2000, 35, 1278-1283.

(40) Nägler, D. K.; Storer, A. C.; Portaro, F. C. V.; Carmona, E.; Juliano, L.; Ménard, R., Major Increase in Endopeptidase Activity of Human Cathepsin B upon Removal of Occluding Loop Contacts. Biochemistry 1997, 36, 12608-12615.

(41) Therrien, C.; Lachance, P.; Sulea, T.; Purisima, E. O.; Qi, H.; Ziomek, E.; AlvarezHernandez, A.; Roush, W. R.; Menard, R., Cathepsins X and B Can Be Differentiated Through 
Their Respective Mono- and Dipeptidyl Carboxypeptidase Activities. Biochemistry 2001, 40, 2702-2711. 
For Table of Contents (TOC) Only 


\section{Supporting Information}

\section{Electrochemical Protease Biosensor Based on}

\section{Enhanced AC Voltammetry Using Carbon}

\section{Nanofiber Nanoelectrode Arrays}

Luxi Z. Swisher ${ }^{a}$, Lateef U. Syed ${ }^{a}$, Allan M. Prior ${ }^{a}$, Foram R. Madiyar $^{a}$, Kyle R. Carlson ${ }^{a}$, Thu A.

$$
\text { Nguyen }^{b}, \text { Duy H. Hua }{ }^{a}, \text { Jun } L i^{* a}
$$

a Department of Chemistry, Kansas State University, Manhattan, Kansas 66506, United States;

${ }^{b}$ Department of Diagnostic Medicine/Pathobiology, College of Veterinary Medicine, Kansas

State University, Manhattan, Kansas 66506, United States

* Corresponding author:

Telephone number: (785) 532-0955

Fax number: (785) 532-6666

Email: junli@ksu.edu 


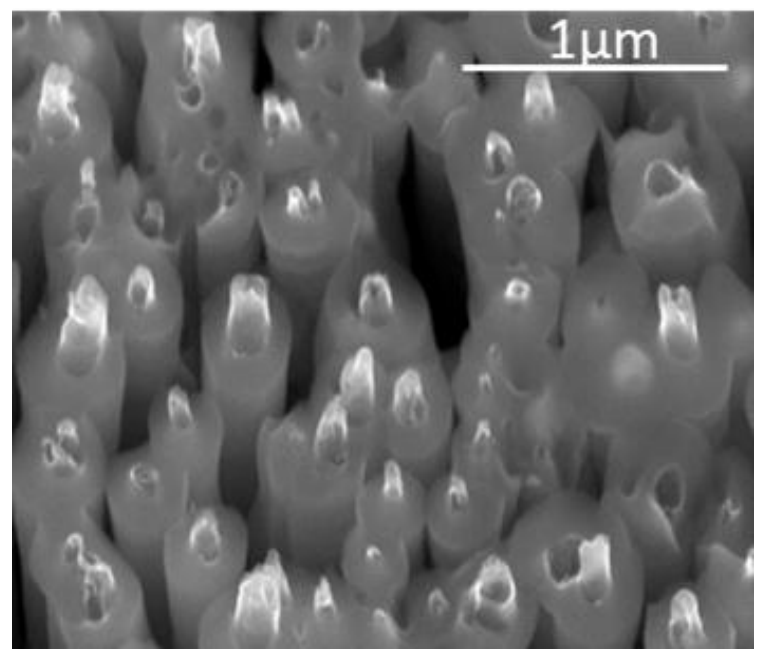

Figure S1. Field-emission scanning electron microscopy image at $45^{\circ}$ perspective view shows that VACNFs of $\sim 150$ $\mathrm{nm}$ in average diameter are encapsulated in $\mathrm{SiO}_{2}$ matrix leaving only the tips exposed.
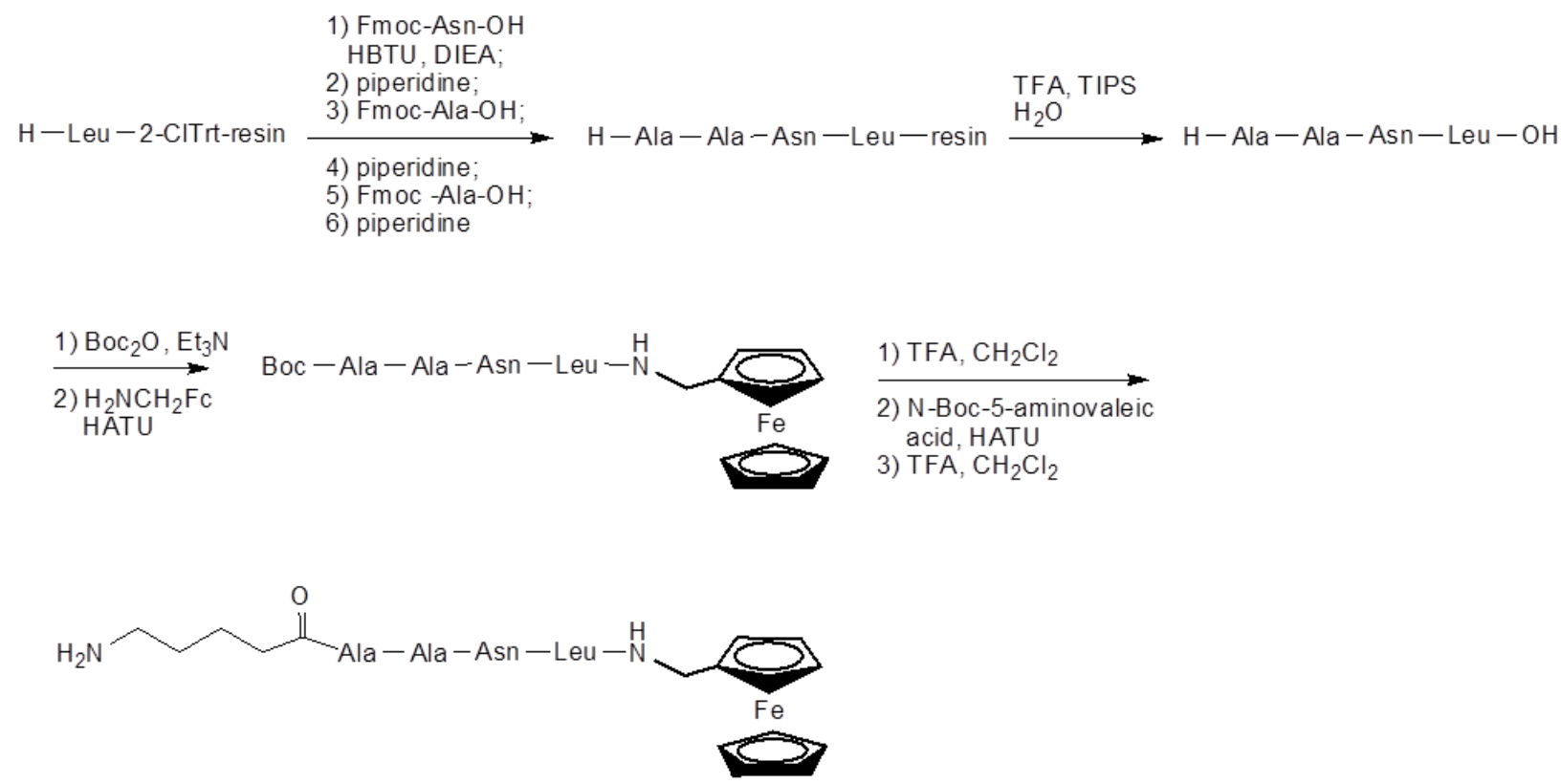

Figure S2. Synthesis of $\mathrm{H}_{2} \mathrm{~N}-\left(\mathrm{CH}_{2}\right)_{4} \mathrm{CO}-\mathrm{Ala}-\mathrm{Ala}-\mathrm{Asn}-\mathrm{Leu}-\mathrm{NHCH}_{2}-\mathrm{Fc}$ for legumain detection.

Experimental Details for Figure S2: Synthesis of $\mathrm{H}_{2} \mathrm{~N}-\left(\mathrm{CH}_{2}\right)_{4} \mathrm{CO}-\mathrm{Ala}-\mathrm{Ala}-\mathrm{Asn}-\mathrm{Leu}-\mathrm{NHCH}_{2}-\mathrm{Fc}$ for legumain detection 
Synthesis of tetrapeptide H-Ala-Ala-Asn-Leu-OH (Figure S2) using a CEM microwave peptide synthesizer. Leucine chlorotrityl resin $(0.54 \mathrm{mmol} / \mathrm{g} ; 200 \mathrm{mesh})$ was purchased from Peptide International. The standard coupling procedure is followed. To $1 \mathrm{~g}(0.54 \mathrm{mmol})$ of resin was added a solution of Fmoc-amino acid (1.62 mmol, 3 equiv.) and HBTU (1.46 mmol, 2.7 equiv.) in dry DMF (13 mL) containing $4.2 \%$ diisopropylethyl amine. The mixture was subjected to microwave irradiation $\left(25 \mathrm{~W}, 5 \mathrm{~min}, 75^{\circ} \mathrm{C}\right)$ with stirring. The reaction mixture was filtered and washed with DMF (10 mL each, 5 times). The standard procedure for the removal of Fmoc protecting group is followed. A solution of $20 \mathrm{~mL}$ of $20 \%$ piperidine in DMF was added to the above resin and subjected to microwave irradiation $\left(50 \mathrm{~W}, 3 \mathrm{~min}, 75^{\circ} \mathrm{C}\right)$. The reaction mixture was filtered and washed with DMF (10 ml each, 5 times). The standard procedure for cleavage of the peptide from resin is followed. The above resin was washed with dichloromethane $(20 \mathrm{~mL})$ and mixed with $20 \mathrm{~mL}$ of a cleavage cocktail solution consists of $95 \%$ trifluoroacetic acid (TFA), 2.5\% triisopropylsilane (TIPS), and 2.5\% water. The mixture was irradiated under a microwave reactor $\left(20 \mathrm{~W}, 38{ }^{\circ} \mathrm{C}\right)$ for $18 \mathrm{~min}$. The reaction mixture was filtered into a $100 \mathrm{~mL}$ flask and diluted with $100 \mathrm{~mL}$ of cold hexane:ether $(1: 1)$ to precipitate out the desired peptide. The solid peptide was collected by centrifugation (2500 rpm) and washed three times with cold hexane:ether (1:1) to give H-Ala-Ala-Asn-Leu-OH as white solids (95 mg). MS calcd for $\mathrm{C}_{16} \mathrm{H}_{30} \mathrm{~N}_{5} \mathrm{O}_{6}(\mathrm{M}+\mathrm{H})^{+}$388.2, found 388.4.

Synthesis of Boc-Ala-Ala-Asn-Leu-OH. To a solution of H-Ala-Ala-Asn-Leu-OH (50 mg, $0.13 \mathrm{mmol})$ were added triethylamine $(36 \mu \mathrm{L}, 0.26 \mathrm{mmol})$ and dioxane:water $(1: 1)(10 \mathrm{~mL})$, and the resulting solution was stirred for $10 \mathrm{~min}$. To it, di-t-butyl dicarbonate $\left(\mathrm{Boc}_{2} \mathrm{O}\right)(56 \mathrm{mg}, 0.26$ mmol) was added and the solution stirred for $12 \mathrm{~h}$ at r.t. The reaction solution was concentrated to dryness yielding Boc-Ala-Ala-Asn-Leu-OH as a white solid (60 mg; 96\% yield). MS calcd for $\mathrm{C}_{21} \mathrm{H}_{37} \mathrm{~N}_{5} \mathrm{NaO}_{8}(\mathrm{M}+\mathrm{Na})^{+}$510.3, found 510.4.

Synthesis of Boc-Ala-Ala-Asn-Leu-NHCH$-\mathbf{N c}$. To a solution of Boc-Ala-Ala-Asn-Leu-OH (60 mg, $0.12 \mathrm{mmol})$ in DMF (2 mL) under argon was added HATU (47 mg, $0.12 \mathrm{mmol}$ ) and the solution was stirred for $10 \mathrm{~min}$. To it, aminomethylferrocene (26 mg, $0.12 \mathrm{mmol}$ ) was added, and the solution was stirred at r.t. for $2 \mathrm{~h}$, filtered, and separated on a HPLC using a preparative column (Phenomenex-Jupiter C18) and eluting with $40 \%$ acetonitrile/water to $80 \%$ acetonitrile/water over $40 \mathrm{~min}$ with a $10 \mathrm{ml} / \mathrm{min}$ flow rate. The fractions containing the desired 
product were combined and lyophilized to yield Boc-HN-Ala-Ala-Asn-Leu- $\mathrm{NHCH}_{2}-\mathrm{Fc}$ as a yellow solid (40 mg; 48\% yield). MS calcd for $\mathrm{C}_{32} \mathrm{H}_{48} \mathrm{FeN}_{6} \mathrm{NaO}_{7}(\mathrm{M}+\mathrm{Na})^{+}$707.3, found 707.5.

Synthesis of $\mathbf{H}_{2} \mathbf{N}$-Ala-Ala-Asn-Leu-NHCH $\mathbf{H}_{2}$-Fc. Boc-Ala-Ala-Asn-Leu-NHCH $-\mathrm{Fc}(18 \mathrm{mg}, 26$ $\mu \mathrm{mol}$ ) was dissolved in $2 \mathrm{~mL}$ of $10 \%$ TFA in dichloromethane and stirred at r.t. for $30 \mathrm{~min}$, concentrated gently on a rotovap to give a residue. The residue was dissolved in deionized water ( $2 \mathrm{~mL}$ ), frozen, and lyophilized to give H-Ala-Ala-Asn-Leu- $\mathrm{NHCH}_{2}-\mathrm{Fc}$ as a green solid (15 mg; $100 \%$ yield). MS calcd for $\mathrm{C}_{27} \mathrm{H}_{40} \mathrm{FeN}_{6} \mathrm{NaO}_{5}(\mathrm{M}+\mathrm{Na})^{+}$607.2, found 607.3.

Synthesis of Boc-HN- $\left(\mathrm{CH}_{2}\right)_{4} \mathrm{CO}-\mathrm{Ala}-\mathrm{Ala}-\mathrm{Asn}-\mathrm{Leu}-\mathrm{NHCH}_{2}-\mathrm{Fc}$. To a solution of $\mathrm{N}$-Boc-5aminovaleric acid (5.6 mg, $26 \mu \mathrm{mol})$ in DMF ( $2 \mathrm{~mL}$ ) was added HATU (9 mg, $24 \mu \mathrm{mol})$, and the resulting solution was stirred at r.t. for $10 \mathrm{~min}$. This solution was cannulated to tetrapeptide $\mathrm{H}$ Ala-Ala-Asn-Leu- $\mathrm{NHCH}_{2}-\mathrm{Fc}(10 \mathrm{mg}, 17 \mu \mathrm{mol})$, and the resulting solution was stirred for $2 \mathrm{~h}$ at r.t., filtered, and separated on a HPLC using a preparative column (Phenomenex-Jupiter C18) and eluting with $40 \%$ acetonitrile/water to $80 \%$ acetonitrile/water over $40 \mathrm{~min}$ with a $10 \mathrm{ml} / \mathrm{min}$ flow rate. The fractions containing the desired product were combined and lyophilized to yield Boc$\mathrm{HN}-\left(\mathrm{CH}_{2}\right)_{4} \mathrm{CO}$-Ala-Ala-Asn-Leu-NHCH $\mathrm{H}_{2}-\mathrm{Fc}$ as a yellow solid (6 mg; $45 \%$ yield). MS calcd for $\mathrm{C}_{37} \mathrm{H}_{57} \mathrm{FeN}_{7} \mathrm{NaO}_{8}(\mathrm{M}+\mathrm{Na})^{+}$806.4, found 806.5.

HPLC method: (gradient elution), $\lambda=254 \mathrm{~nm}$

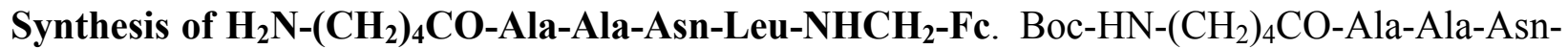
Leu- $\mathrm{NHCH}_{2}-\mathrm{Fc}(6 \mathrm{mg}, 8 \mu \mathrm{mol})$ was dissolved in $1 \mathrm{~mL}$ of $10 \%$ TFA in dichloromethane and stirred at r.t. for $30 \mathrm{~min}$. The reaction solution was concentrated gently on a rotary evaporator to give a residue which was dissolved in deionized water $(2 \mathrm{~mL})$, frozen and lyophilized to give $\mathrm{H}_{2} \mathrm{~N}-\left(\mathrm{CH}_{2}\right)_{4} \mathrm{CO}-\mathrm{Ala}-\mathrm{Ala}-\mathrm{Asn}-\mathrm{Leu}-\mathrm{NHCH}_{2}-\mathrm{Fc}$ as a green solid (4 mg; $75 \%$ yield). MS calcd for $\mathrm{C}_{32} \mathrm{H}_{50} \mathrm{FeN}_{7} \mathrm{O}_{6}(\mathrm{M}+\mathrm{H})^{+}$684.3, found 684.4. 

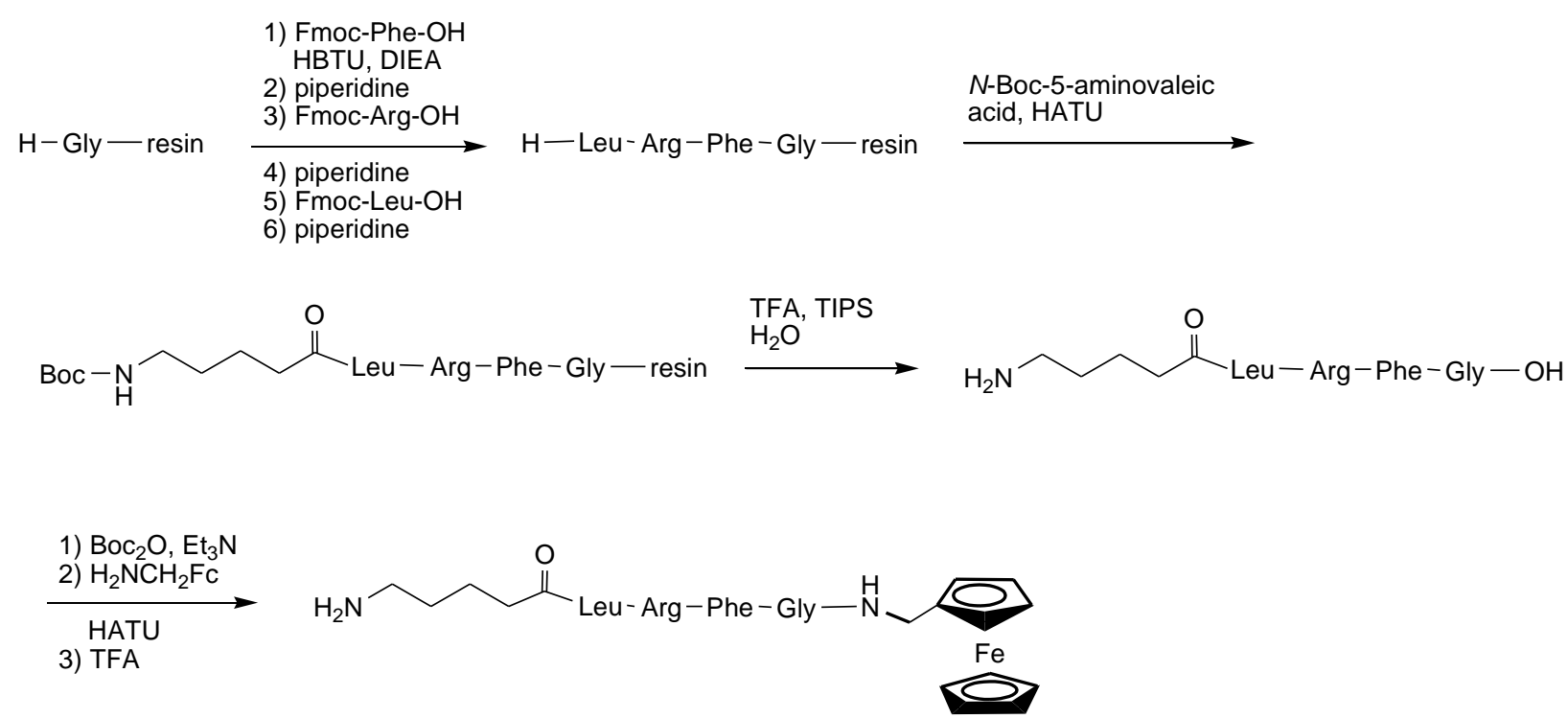

Figure S3. Synthesis of $\mathrm{H}_{2} \mathrm{~N}-\left(\mathrm{CH}_{2}\right)_{4} \mathrm{CO}-\mathrm{Leu}-\mathrm{Arg}-\mathrm{Phe}-\mathrm{Gly}-\mathrm{NHCH}_{2}-\mathrm{Fc}$ for cathepsin B detection.

Experimental Details for Figure S3: Synthesis of $\mathrm{H}_{2} \mathrm{~N}-\left(\mathrm{CH}_{2}\right)_{4} \mathrm{CO}-\mathrm{Leu}-\mathrm{Arg}-\mathrm{Phe}-\mathrm{Gly}-\mathrm{NHCH}_{2}-$

Fc for cathepsin B detection

Synthesis of tetrapeptide $\mathrm{H}_{2} \mathrm{~N}-\left(\mathrm{CH}_{2}\right)_{4} \mathrm{CO}-\mathrm{Leu}-\mathrm{Arg}-\mathrm{Phe}-\mathrm{Gly}-\mathrm{OH}$ (Figure S3) using a CEM microwave peptide synthesizer. The Glycine chlorotrityl resin $(0.48 \mathrm{mmol} / \mathrm{g} ; 200 \mathrm{mesh})$ was purchased from peptide international. The procedures for coupling, removal of Fmoc protecting group, and cleavage from the resin were identical to that described above for the synthesis of legumain substrate. From $1.2 \mathrm{~g}(0.57 \mathrm{mmol})$ of Glycine chlorotritylresin, $0.32 \mathrm{~g}$ (94\% yield) of $\mathrm{H}_{2} \mathrm{~N}-\left(\mathrm{CH}_{2}\right)_{4} \mathrm{CO}-\mathrm{Leu}$-Arg-Phe-Gly-OH was obtained as a white solid. MS calcd for $\mathrm{C}_{28} \mathrm{H}_{47} \mathrm{~N}_{8} \mathrm{O}_{6}$ $(\mathrm{M}+\mathrm{H})^{+}$591.4, found 591.2.

Synthesis of Boc-HN-(CH$)_{4}$ CO-Leu-Arg-Phe-Gly-OH. A solution of sodium bicarbonate (86 $\mathrm{mg}, 1.2 \mathrm{mmol})$ and $\mathrm{H}_{2} \mathrm{~N}-\left(\mathrm{CH}_{2}\right)_{4} \mathrm{CO}-\mathrm{Leu}-$ Arg-Phe-Gly-OH $(0.300 \mathrm{~g}, 0.5 \mathrm{mmol})$ in $30 \mathrm{~mL}$ of dioxane:water $(1: 1)$ was stirred at r.t. for $10 \mathrm{~min}$. To it, di-t-butyl dicarbonate $\left(\mathrm{Boc}_{2} \mathrm{O}\right)(0.22 \mathrm{~g}$, $1.2 \mathrm{mmol}$ ) was added, and the solution stirred for $12 \mathrm{~h}$, concentrated to dryness yielding a white solid (0.35 g; 99\% yield). MS calcd for $\mathrm{C}_{33} \mathrm{H}_{55} \mathrm{~N}_{8} \mathrm{O}_{8}(\mathrm{M}+\mathrm{H})^{+}$691.4, found 691.7. 
Synthesis of Boc-HN-( $\left(\mathrm{CH}_{2}\right)_{4} \mathrm{CO}-\mathrm{Leu}-\mathrm{Arg}-\mathrm{Phe}-\mathrm{Gly}-\mathrm{NHCH}_{2}-\mathrm{Fc}$. A solution of Boc$\mathrm{NH}\left(\mathrm{CH}_{2}\right)_{4} \mathrm{CO}-\mathrm{Leu}-\mathrm{Arg}$-Phe-Gly-OH $(60 \mathrm{mg}, 0.09 \mathrm{mmol})$ and HATU $(47 \mathrm{mg}, 0.12 \mathrm{mmol})$ in DMF ( $2 \mathrm{~mL}$ ) was stirred at r.t. for $10 \mathrm{~min}$. To it, aminomethylferrocene (26 $\mathrm{mg}, 0.12 \mathrm{mmol})$ was added, and the solution was stirred for $2 \mathrm{~h}$, filtered, and separated on a HPLC using a preparative column (Phenomenex-Jupiter C18) and eluting with $40 \%$ acetonitrile/water to $80 \%$ acetonitrile/water over $40 \mathrm{~min}$ with a $10 \mathrm{ml} / \mathrm{min}$ flow rate. The fractions containing the desired product were combined and lyophilized to yield Boc-HN- $\left(\mathrm{CH}_{2}\right)_{4} \mathrm{CO}-\mathrm{Leu}-\mathrm{Arg}-\mathrm{Phe}-\mathrm{Gly}-\mathrm{NHCH}_{2}-$ Fc as a yellow solid (40 mg; $50 \%$ yield). MS calcd for $\mathrm{C}_{44} \mathrm{H}_{66} \mathrm{FeN}_{9} \mathrm{O}_{7}(\mathrm{M}+\mathrm{H})^{+}$888.4, found 888.6.

Synthesis of $\mathrm{H}_{2} \mathrm{~N}-\left(\mathrm{CH}_{2}\right)_{4} \mathrm{CO}-\mathrm{Leu}-\mathrm{Arg}-\mathrm{Phe}-\mathrm{Gly}-\mathrm{NHCH}_{2}$-Fc. A solution of Boc-HN$\left(\mathrm{CH}_{2}\right)_{4} \mathrm{CO}-$ Leu-Arg-Phe-Gly-NHCH$-\mathrm{Fc}(50 \mathrm{mg} ; 56 \mu \mathrm{mol})$ in $2 \mathrm{~mL}$ of $10 \%$ TFA in dichloromethane was stirred at r.t. for $30 \mathrm{~min}$, concentrated gently on a rotary evaporator, dissolved in deionized water ( $2 \mathrm{~mL}$ ), frozen, and lyophilized to give $\mathrm{H}_{2} \mathrm{~N}-\left(\mathrm{CH}_{2}\right)_{4} \mathrm{CO}-\mathrm{Leu}$-ArgPhe-Gly- $\mathrm{NHCH}_{2}-\mathrm{Fc}$ as a green solid $\left(43 \mathrm{mg}\right.$; $98 \%$ yield). MS calcd for $\mathrm{C}_{39} \mathrm{H}_{58} \mathrm{FeN}_{9} \mathrm{O}_{5}(\mathrm{M}+\mathrm{H})^{+}$ 788.4, found 788.5 .

Verification of the inactivity of the guanidine NH function of arginine residue of Boc-HN$\left(\mathrm{CH}_{2}\right)_{4} \mathbf{C O}$-Leu-Arg-Phe-Gly-NHCH$-\mathbf{F c}$. The following reaction has been carried out to verify that the guanidine $\mathrm{NH}$ function of arginine residue of Boc-HN- $\left(\mathrm{CH}_{2}\right)_{4} \mathrm{CO}-\mathrm{Leu}-\mathrm{Arg}-\mathrm{Phe}-\mathrm{Gly}-$ $\mathrm{NHCH}_{2}-\mathrm{Fc}$ does not form amide bond with the carboxylic function on carbon nanofibers. To a 1 $\mathrm{mL}$ aqueous solution of Boc-HN-($\left(\mathrm{CH}_{2}\right)_{4} \mathrm{CO}-\mathrm{Leu}-\mathrm{Arg}-\mathrm{Phe}-\mathrm{Gly}-\mathrm{NHCH}_{2}-\mathrm{Fc}(3 \mathrm{mg}, 3.4 \mu \mathrm{mol})$, benzoic acid $(0.4 \mathrm{mg}, 3.4 \mu \mathrm{mol})$, and $N$-hydroxysuccinimide $(0.4 \mathrm{mg}, 3.4 \mu \mathrm{mol})$ was added with 1-ethyl-3-(3-dimethylaminopropyl)carbodiimide hydrochloride $(0.66 \mathrm{mg}, 3.4 \mu \mathrm{mol})$, and the resulting solution was stirred at room temperature for 2 hours. Mass spectrometry analysis showed that no reaction took place between the $\mathrm{NH}$ group of arginine residue and the carboxylic acid moiety of benzoic acid. Boc-HN- $\left(\mathrm{CH}_{2}\right)_{4} \mathrm{CO}-\mathrm{Leu}-\mathrm{Arg}-\mathrm{Phe}-\mathrm{Gly}-\mathrm{NHCH}_{2}-\mathrm{Fc}$ remained unchanged. The test suggested that the $\mathrm{NH}$ moieties in the side chain of arginine residue does not react with the carboxylic acid function of carbon nanofibers. The most likely route for the peptide to be attached to the VACNF NEA is by forming the amide bond through the $-\mathrm{NH}_{2}$ group at the distal end of the linker (as shown in Figure S3). 

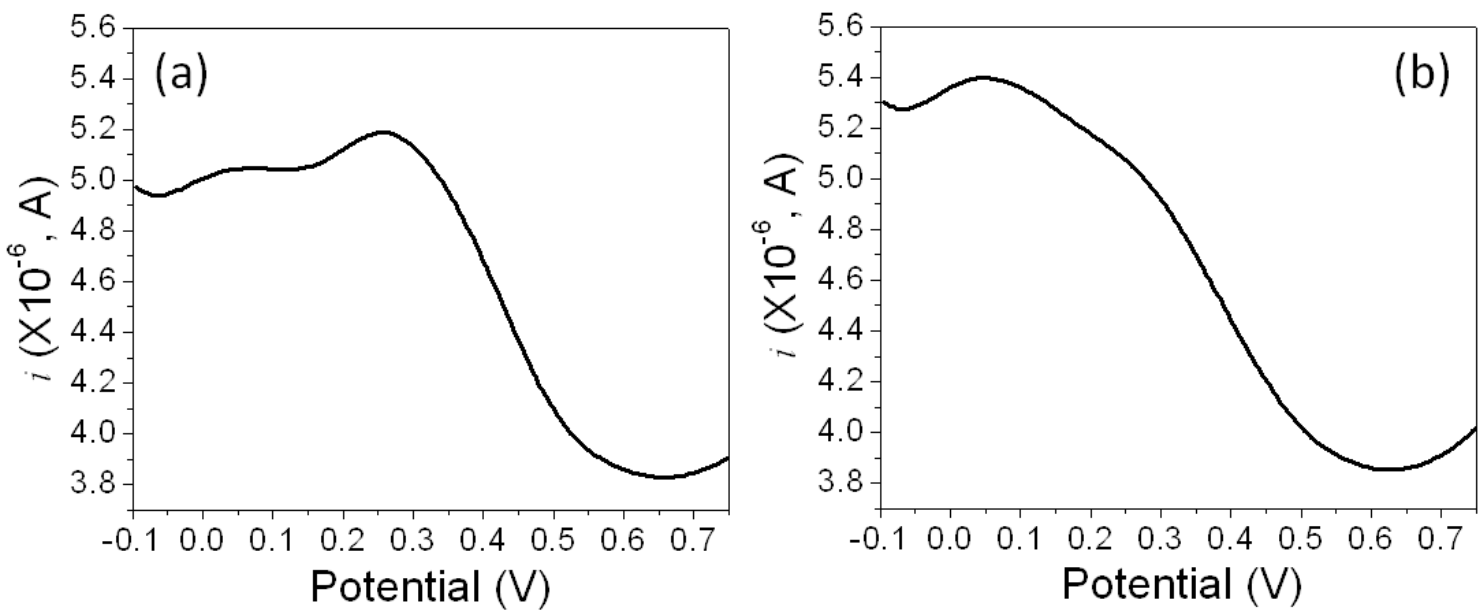

Figure S4. The ACV of $\mathrm{H}_{2} \mathrm{~N}-\left(\mathrm{CH}_{2}\right)_{4}-\mathrm{CO}-\mathrm{Leu}-\mathrm{Arg}-\mathrm{Phe}-\mathrm{Gly}-\mathrm{NH}-\mathrm{CH}_{2}-\mathrm{Fc}$ immobilized on the GCE (a) from the initial measurement and (b) from the measurement after 20 minutes. The AC frequency was $30 \mathrm{~Hz}$ and the amplitude was $25 \mathrm{mV}$. The measurement was done in $250 \mu \mathrm{L}$ of $25 \mathrm{mM}$ MES solution (pH 5.0). 
(a)

(b)
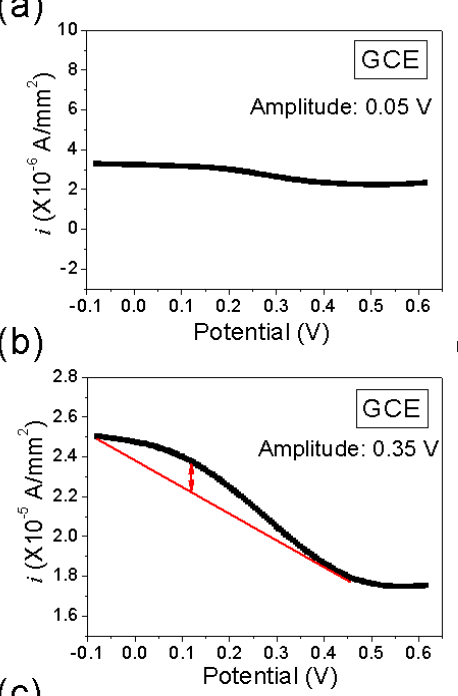

(c)

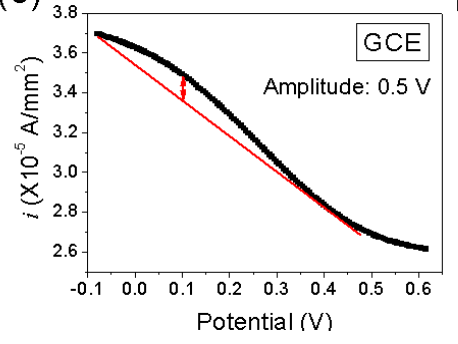

(d)

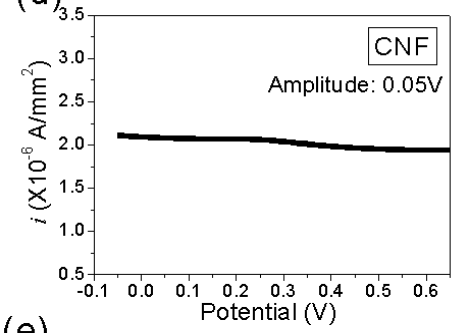

(e)

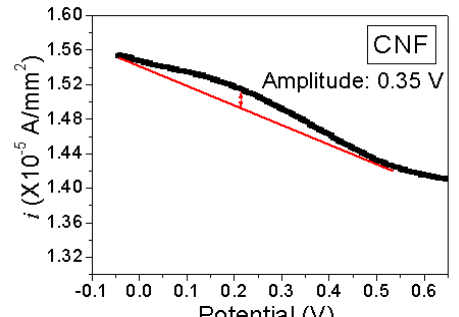

(f)

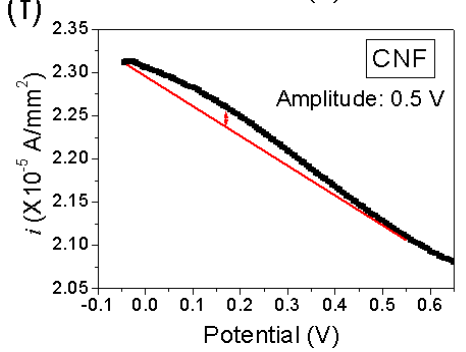

Figure S5. Comparison of AC voltammograms (ACVs) of $\mathrm{H}_{2} \mathrm{~N}-\left(\mathrm{CH}_{2}\right)_{4}-\mathrm{CO}-\mathrm{Ala}-\mathrm{Ala}-\mathrm{Asn}-\mathrm{Leu}-\mathrm{NH}-\mathrm{CH}_{2}-\mathrm{Fc}$ immobilized on a macroscopic glassy carbon electrode (GCE) (a-c) and a VACNF NEA (d-f) at the AC voltage amplitude of $0.05,0.35$ and $0.5 \mathrm{~V}$. All the measurements were done in $500 \mu \mathrm{L}$ of $50 \mathrm{mM} \mathrm{MES} \mathrm{(pH} \mathrm{5.0)} \mathrm{and} 250 \mathrm{mM}$ $\mathrm{NaCl}$. Sinusoidal waves with fixed frequency of $40 \mathrm{~Hz}$ for GCE and frequency of $1750 \mathrm{~Hz}$ for CNF NEA were superimposed on a DC staircase ramp from -0.05 to $0.65 \mathrm{~V}$ at a scan rate of $10 \mathrm{mV} / \mathrm{s}$. The measured average AC current at each point was normalized by the $7.1 \mathrm{~mm}^{2}$ geometric surface area defined by the 3 -mm i.d. O-ring. The real CNF surface area is $\sim 100$ times less. 

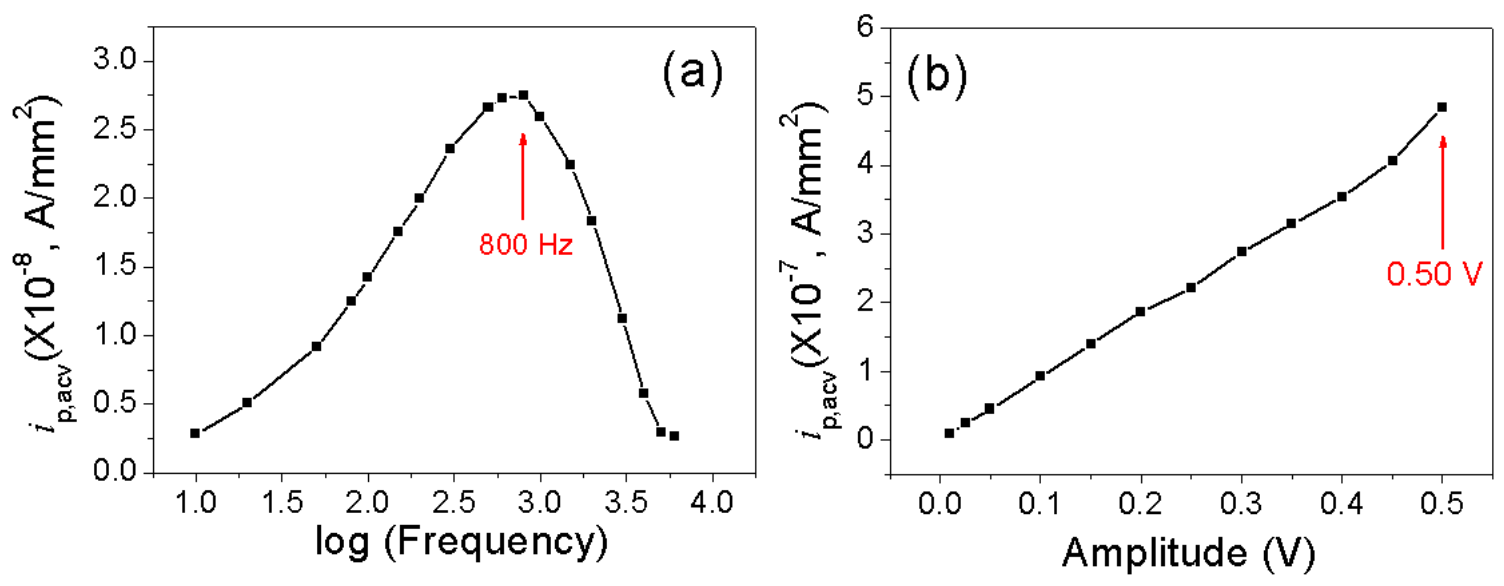

Figure S6. (a) Background-corrected ACV peak current density $i_{\text {pacv }}$ (normalized to the $7.1 \mathrm{~mm}^{2}$ geometric electrode area) of $\mathrm{H}_{2} \mathrm{~N}-\left(\mathrm{CH}_{2}\right)_{4}$-CO-Leu-Arg-Phe-Gly-NH- $\mathrm{CH}_{2}-\mathrm{Fc}$ immobilized on a VACNF NEA plotted against the logarithm of the frequency. (b) Background-corrected ACV peak current density $i_{\mathrm{p} \text {,acv }}$ (normalized to the $7.1 \mathrm{~mm}^{2}$ geometric electrode area) of $\mathrm{H}_{2} \mathrm{~N}-\left(\mathrm{CH}_{2}\right)_{4}$-CO-Leu-Arg-Phe-Gly-NH- $\mathrm{CH}_{2}-\mathrm{Fc}$ immobilized on a VACNF NEA plotted against the amplitude. All the measurements were done in $250 \mu \mathrm{L}$ of $25 \mathrm{mM}$ MES (pH 5.0). Note: The real CNF surface area is $\sim 100$ times less than the geometric surface area defined by the O-ring. 

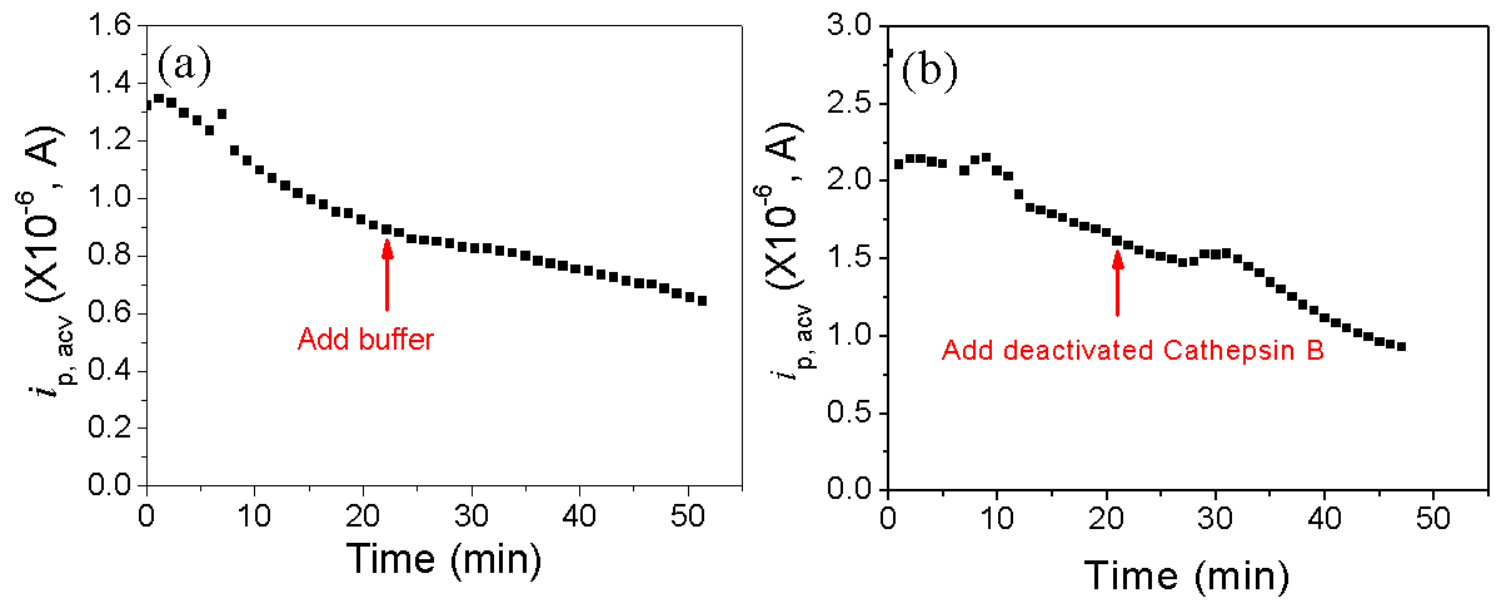

Figure S7. Negative control experiments. The change of the peak current $\left(i_{p, a c v}\right)$ of $\mathrm{H}_{2} \mathrm{~N}-\left(\mathrm{CH}_{2}\right)_{4}-\mathrm{CO}-\mathrm{Leu}-\mathrm{Arg}-\mathrm{Phe}-$ Gly-NH- $\mathrm{CH}_{2}$-Fc immobilized on a VACNF NEA in continuously repeated ACV measurements while (a) $25 \mu \mathrm{L}$ of activation buffer consisting of $5 \mathrm{mM}$ DTT and $25 \mathrm{mM}$ MES (pH 5.0) and (b) the same buffer containing $9.8 \mathrm{ng} \mu \mathrm{L}^{-1}$ $(338 \mathrm{nM}$ ) deactivated cathepsin B were added into the electrochemical cell containing $250 \mu \mathrm{L}$ of $25 \mathrm{mM} \mathrm{MES} \mathrm{(pH}$ 5.0). All ACV measurements were carried out at $f=800 \mathrm{~Hz}$ and $\mathrm{AC}$ voltage amplitude $\mathrm{V}_{0}=150 \mathrm{mV}$.
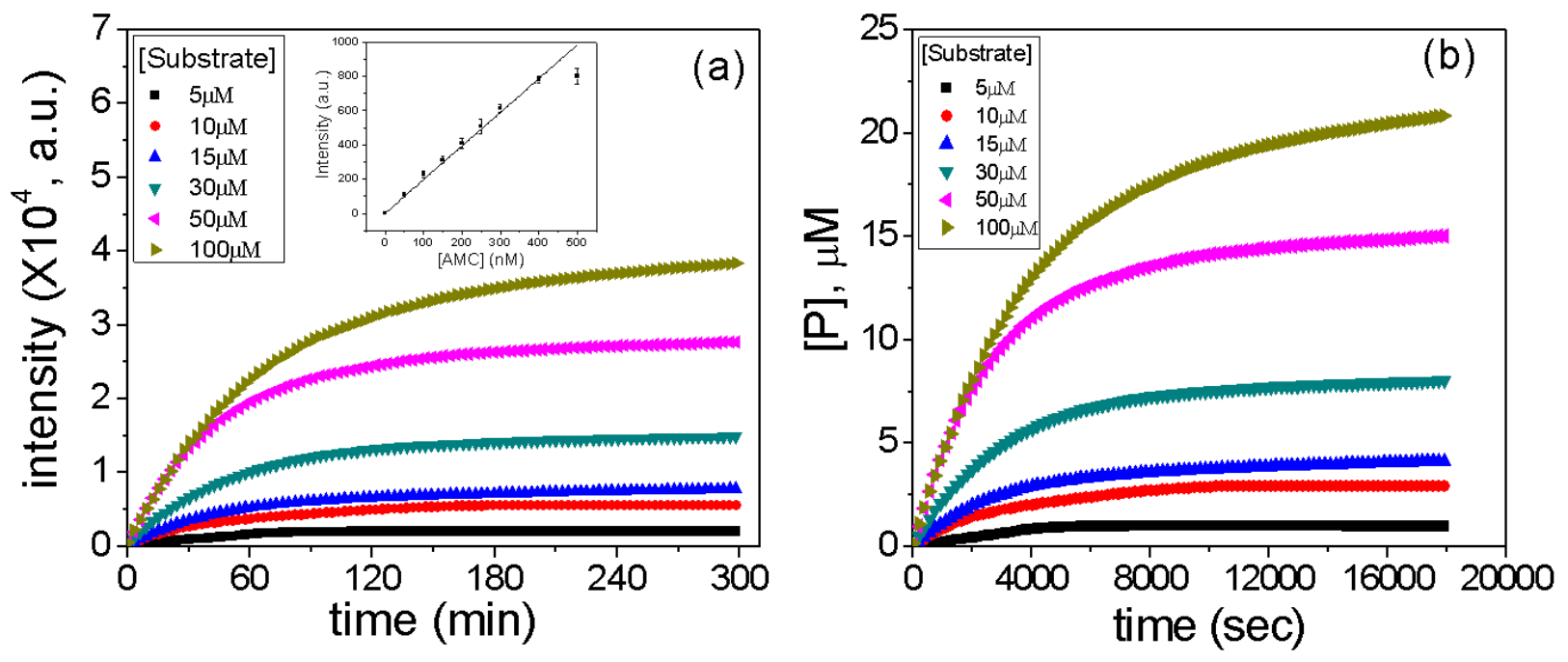
Figure S8. (a) The kinetic curves of the fluorescence intensity of $0.1 \mathrm{ng} \mu \mathrm{L}^{-1}(3.45 \mathrm{nM})$ cathespin B reacting with different concentrations of substrate Z-Leu-Arg-AMC in $25 \mathrm{mM}$ MES (pH 5.0). The cleavage between Arg and AMC released free AMC products which were strongly fluorescent and gave the increased fluorescence intensity. Inset: calibration curve of the fluorometer. (Excitation wavelength: $365 \mathrm{~nm}$, emission wavelength: $410-460 \mathrm{~nm}$ ) (b) The calibrated concentration of free AMC product during cathepsin B cleavage of various concentrations of substrate Z-Leu-Arg-AMC.
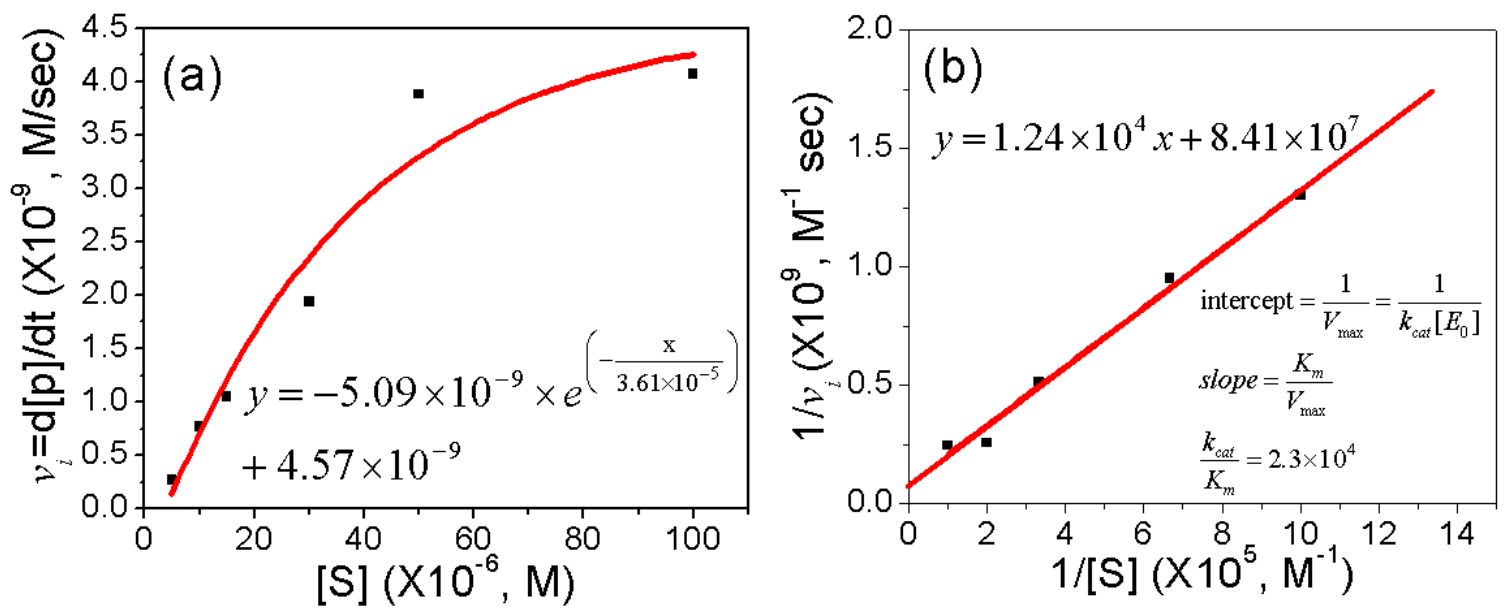

Figure S9. (a) The initial proteolysis reaction rate $v_{i}$ of cathepsin B plotted against the starting concentration of the substrate Z-Leu-Arg-AMC. The reaction rate was calculated from the slope of the tangent of the initial segment of the curves shown in Figure S8b. (b) Replot of the data presented in (a) and derivation of various catalytic constants. The value of $k_{\text {cat }} / \mathrm{K}_{\mathrm{m}}$ for cathepsin B was calculated as $2.3 \times 10^{4} \mathrm{M}^{-1} \mathrm{~s}^{-1}$. 

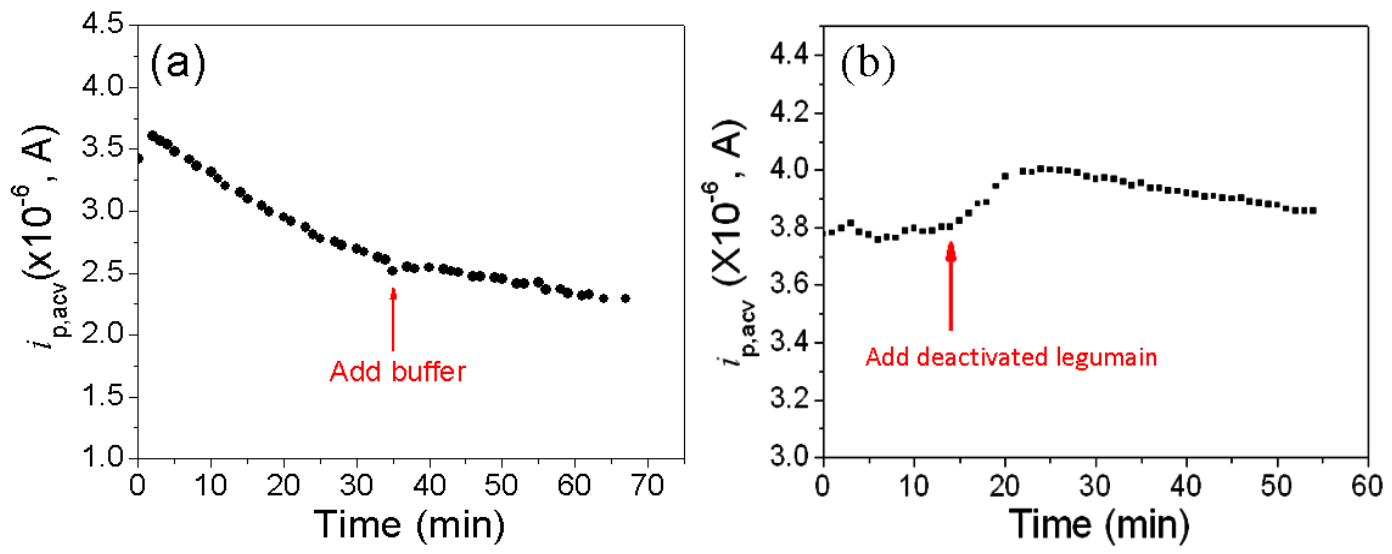

Figure S10. Negative control experiments for legumain proteolysis. The change of the peak current $\left(i_{p, a c v}\right)$ of $\mathrm{H}_{2} \mathrm{~N}-$ $\left(\mathrm{CH}_{2}\right)_{4}$-CO-Ala-Ala-Asn-Leu-NH- $\mathrm{CH}_{2}-\mathrm{Fc}$ immobilized on a VACNF NEA in continuously repeated ACV measurements (a) while $11 \mu \mathrm{L}$ of activation buffer consisting of $50 \mathrm{mM} \mathrm{CH}_{3} \mathrm{COONa}(\mathrm{pH}=4.0$, adjusted by adding acetic acid) and $100 \mathrm{mM} \mathrm{NaCl}$ was added into the electrochemical cell containing $250 \mu \mathrm{L}$ of $50 \mathrm{mM}$ MES (pH 5.0) and $250 \mathrm{mM} \mathrm{NaCl}$; (b) similar experiments by including $90.9 \mathrm{ng} \mu \mathrm{L}^{-1}(1.90 \mu \mathrm{M})$ deactivated legumain in the activation buffer. All ACV measurements were carried out at $f=1750 \mathrm{~Hz}$ and AC voltage amplitude $\mathrm{V}_{0}=150 \mathrm{mV}$. 

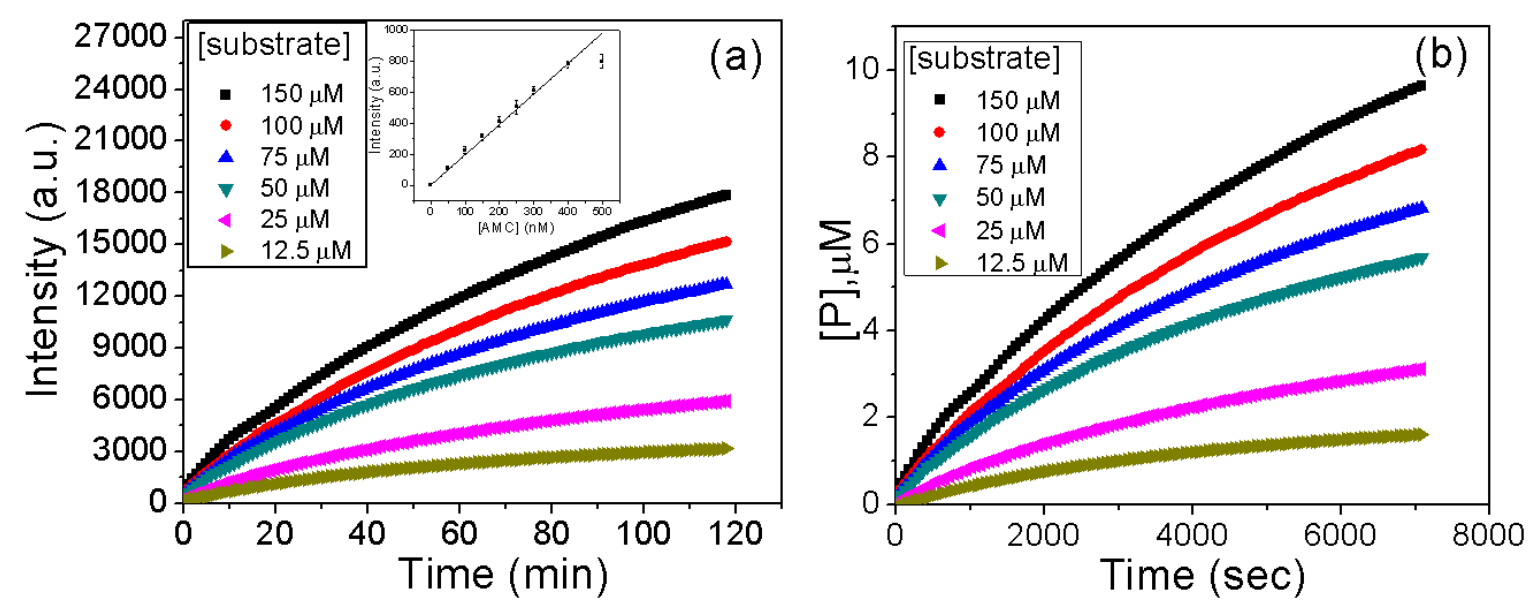

Figure S11. (a) The fluorescence intensity curves of $0.5 \mathrm{ng} \mu \mathrm{L}^{-1}(10.2 \mathrm{nM})$ legumain reacting with different concentration of substrate Z-Ala-Ala-Asn-AMC in the assay buffer consisting of $50 \mathrm{mM}$ MES (pH 5.0) and $250 \mathrm{mM}$ $\mathrm{NaCl}$. Inset: calibration curve of the fluorometer. (excitation wavelength: $365 \mathrm{~nm}$, emission wavelength: 410-460 nm). (b) The calibrated free AMC product concentration during legumain cleavage the substrate Z-Ala-Ala-AsnAMC.
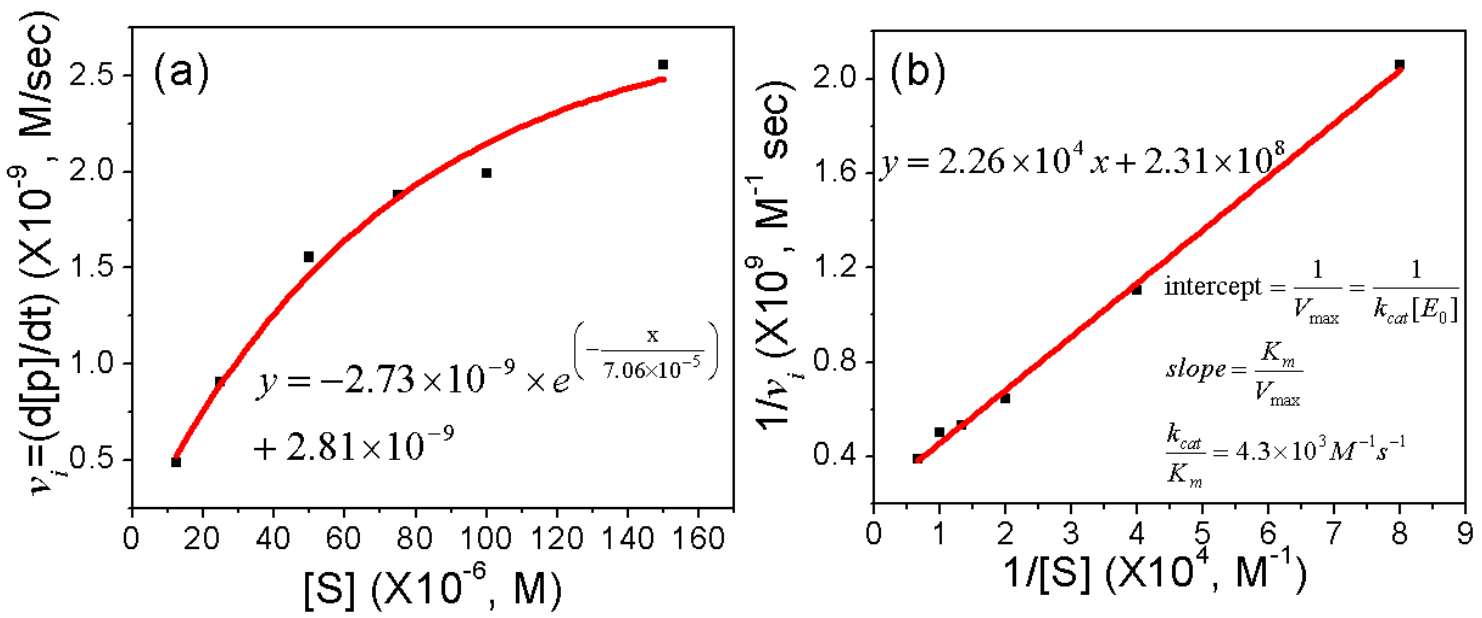

Figure S12. (a) The initial proteolysis reaction rate $v_{i}$ of legumain plotted against the concentration of the substrate Z-Ala-Ala-Asn-AMC. The reaction rate was calculated from the slope of the tangent of the initial segment of the 
curves shown in Figure S11b. (b) Replot of the data presented in (a) and the derivation of various catalytic constants. The value of $k_{\text {cat }} / \mathrm{K}_{\mathrm{m}}$ for legumain was calculated as $4.3 \times 10^{3} \mathrm{M}^{-1} \mathrm{~s}^{-1}$.

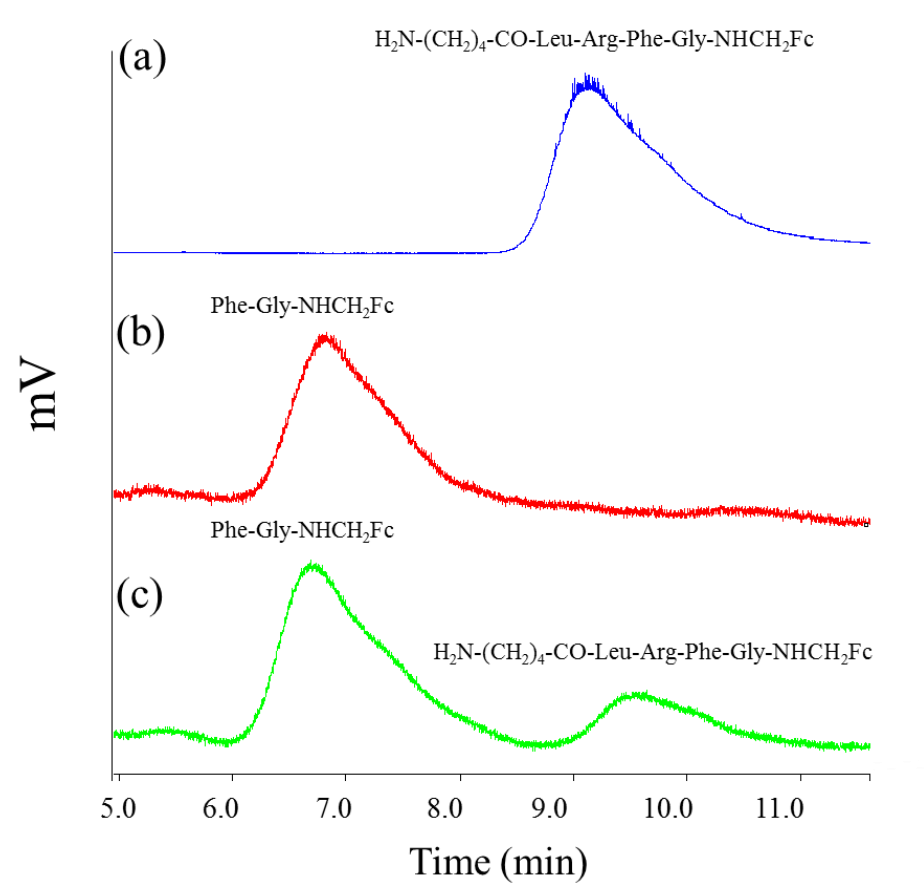

Figure S13. (a) HPLC chart of $\mathrm{H}_{2} \mathrm{~N}-\left(\mathrm{CH}_{2}\right)_{4}$-CO-Leu-Arg-Phe-Gly- $\mathrm{NHCH}_{2} \mathrm{Fc}$ in $25 \mathrm{mM} \mathrm{MES}$ (pH 5.0) buffer. The tetrapeptide appeared at 9.4 minute in the HPLC chart and its structure was verified by mass spectrometry analysis. (b) HPLC chart of Phe-Gly- $\mathrm{NHCH}_{2} \mathrm{Fc}$ in $25 \mathrm{mM}$ MES (pH 5.0) buffer. The dipeptide appeared at 6.7 minute in the HPLC chart and its structure was verified by mass spectrometry analysis. (c) HPLC chart of $6.35 \mathrm{mM} \mathrm{H}{ }_{2} \mathrm{~N}-\left(\mathrm{CH}_{2}\right)_{4}$-CO-Leu-ArgPhe-Gly-NHCH${ }_{2} \mathrm{Fc}$ in $25 \mathrm{mM}$ MES (pH 5.0) buffer incubated with $4.95 \mathrm{ng} \mu \mathrm{l}^{-1}(0.17 \mu \mathrm{M})$ cathepsin B for 2 hours. Absorbance peak at 6.7 minute was collected and lyophilized and mass spectrometry analysis showed it to be Phe-Gly-NHCH${ }_{2} \mathrm{Fc}$. HPLC Method: a gradient elution from $10 \%$ to $50 \%$ of acetonitrile in $0.1 \mathrm{M}$ phosphate buffer $(\mathrm{pH}=6)$ over 40 minutes was used with a flow rate of $10 \mathrm{ml} / \mathrm{min}$ and detection wavelength $\lambda$ at $254 \mathrm{~nm}$. The column is Xperchrom AEGIS C18 120A $10 \mu \mathrm{m}$ (Phenomenex). 


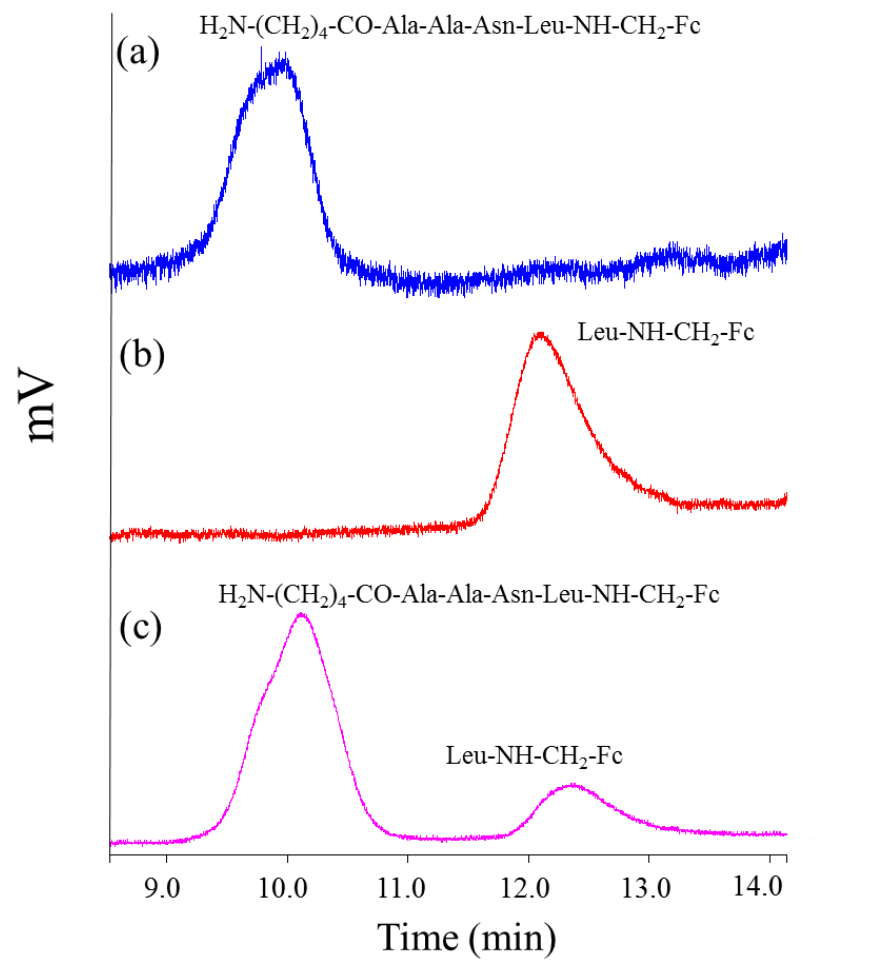

Figure S14. (a) HPLC chart of $\mathrm{H}_{2} \mathrm{~N}-\left(\mathrm{CH}_{2}\right)_{4}$-CO-Ala-Ala-Asn-Leu- $\mathrm{NHCH}_{2} \mathrm{Fc}$ in $50 \mathrm{mM}$ MES (pH 5.0) and $250 \mathrm{mM}$ $\mathrm{NaCl}$. The tetrapeptide appeared at 9.7 minute in the HPLC chart and its structure was verified by mass spectrometry analysis. (b) HPLC chart of Leu- $\mathrm{NHCH}_{2} \mathrm{Fc}$ in $50 \mathrm{mM}$ MES (pH 5.0) and $250 \mathrm{mM} \mathrm{NaCl}$. The Leu- $\mathrm{NHCH}_{2} \mathrm{Fc}$ appeared at 12.2 min in the HPLC chart and its structure was verified by mass spectrometry analysis. (c) HPLC chart of $100 \mu \mathrm{M} \mathrm{H}_{2} \mathrm{~N}-\left(\mathrm{CH}_{2}\right)_{4}$-CO-Ala-Ala-Asn-Leu- $\mathrm{NHCH}_{2} \mathrm{Fc}$ in $50 \mathrm{mM}$ MES (pH 5.0) and $250 \mathrm{mM} \mathrm{NaCl}$ incubated with $98.7 \mathrm{ng} / \mu \mathrm{L}(2.01 \mu \mathrm{M})$ legumain for 2 hours. Absorbance peak at 12.2 min was collected and lyophilized and mass spectrometry analysis showed it to be Leu- $\mathrm{NHCH}_{2} \mathrm{Fc}$. HPLC Method: a gradient elution from $10 \%$ to $50 \%$ of acetonitrile in $0.1 \mathrm{M}$ phosphate buffer $(\mathrm{pH}=6)$ over 40 minutes was used with a flow rate of $10 \mathrm{ml} / \mathrm{min}$ and detection wavelength $\lambda$ at $254 \mathrm{~nm}$. The column is Xperchrom AEGIS C18 120A $10 \mu \mathrm{m}$ (Phenomenex). 
Experimental for Figure S13b: Synthesis of H-Phe-Gly-NHCH $2-\mathrm{Fc}$ for HPLC analysis. BocGly-OH was coupled with $\mathrm{H}_{2} \mathrm{~N}-\mathrm{CH}_{2}-\mathrm{Fc}$ activated by HATU in DMF to yield Boc-Gly- $\mathrm{NHCH}_{2}-$ Fc. The Boc protecting group was removed using 10\% TFA in dichloromethane after which the resulting $\mathrm{H}-\mathrm{Gly}-\mathrm{NHCH}_{2} \mathrm{Fc}$ was coupled with Boc-Phe-OH using EDC and DMAP as activating reagents in dichloromethane to furnish Boc-Phe-Gly-NHCH $2-\mathrm{Fc}$. Removal of Boc protecting group using $10 \%$ TFA in dichloromethane gave H-Phe-Gly-NHCH $2-\mathrm{Fc}$.

Synthesis of Boc-Gly-NHCH $\mathbf{H}_{2}$-Fc. To a solution of Boc-Gly-OH (32 mg, $\left.0.19 \mathrm{mmol}\right)$ in dry DMF under argon was added HATU (77 $\mathrm{mg}, 0.20 \mathrm{mmol})$, and the resulting solution was stirred for 5 minutes. To the above solution, $\mathrm{NH}_{2} \mathrm{CH}_{2}-\mathrm{Fc}(40 \mathrm{mg}, 0.185 \mathrm{mmol})$ was added and the solution stirred at room temperature for 12 hours. The reaction solution was partitioned between $20 \mathrm{~mL}$ of deionized water and $20 \mathrm{~mL}$ of dichloromethane. Organic layer was removed and aqueous layer was extracted once with $20 \mathrm{~mL}$ of dichloromethane. The organic layers were combined and dried $\left(\mathrm{MgSO}_{4}\right)$, filtered, concentrated, and column chromatographed on silica gel using a mixture of dichloromethane and methanol (30:1) as eluant to give $25 \mathrm{mg}$ (36\% yield) of an orange oil. MS calc'd for $\mathrm{C}_{18} \mathrm{H}_{24} \mathrm{FeN}_{2} \mathrm{NaO}_{3} 395.1(\mathrm{M}+\mathrm{Na})^{+}$, found to be 395.1.

Synthesis of H-Gly-NHCH -Fc. To a solution of Boc-Gly-NHCH$-\mathrm{Fc}(25 \mathrm{mg}, 0.092 \mathrm{mmol})$ in $4 \mathrm{~mL}$ of dichloromethane under argon was added $0.4 \mathrm{~mL}$ of trifluoroacetic acid, and the solution was stirred for 1 hour at room temperature. The resulting solution was gently concentrated on a rotary evaporator and placed under high vacuum for 1 hour to yield a green solid. The material is used in the next experiment without purification. MS calc'd for $\mathrm{C}_{13} \mathrm{H}_{17} \mathrm{FeN}_{2} \mathrm{O} 273.1(\mathrm{M}+\mathrm{H})^{+}$, found to be 273.2.

Synthesis of Boc-Phe-Gly-NHCH -Fc. A solution of H-Gly-NHCH $2-F c(25 \mathrm{mg}, 0.092 \mathrm{mmol})$ 
(obtained from the aforementioned experiment), Boc-Phe-OH (24 mg, $0.092 \mathrm{mmol}$ ), 4(dimethylamino)pyridine (23 $\mathrm{mg}, \quad 0.184 \mathrm{mmol})$, and 1-ethyl-3-(3-dimethylaminopropyl) carbodiimide (EDC) (35 mg, $0.184 \mathrm{mmol})$ in $1 \mathrm{~mL}$ of dry DMF under argon was stirred for 1 minute at room temperature. Dry dichloromethane $(2 \mathrm{~mL})$ and additional DMAP (until $\mathrm{pH}$ of the reaction solution was slightly basic) were added, and the reaction solution stirred at room temperature for 12 hours. The reaction mixture was partitioned between $20 \mathrm{~mL}$ of dichloromethane and $20 \mathrm{~mL}$ of deionized water, and $2 \mathrm{~N}$ hydrochloric acid was added until $\mathrm{pH}$ reached about 2 . The organic layer was separated using a separatory funnel, and the aqueous layer was extracted four times $(20 \mathrm{~mL}$ each) with dichloromethane. The combined organic layers were washed with brine, dried (anhydrous $\mathrm{Na}_{2} \mathrm{SO}_{4}$ ), filtered, concentrated, and column chromatographed on silica gel using a mixture of dichloromethane and methanol (40:1) as eluant to give Boc-Phe-Gly-NHCH $2-\mathrm{Fc}$ as a yellow oil (23 mg, $48 \%$ yield). MS calc'd for $\mathrm{C}_{27} \mathrm{H}_{33} \mathrm{FeN}_{3} \mathrm{NaO}_{4} 542.1(\mathrm{M}+\mathrm{Na})^{+}$and found to be 541.9.

Synthesis of H-Phe-Gly-NHCH2-Fc. A solution of Boc-Phe-Gly- $\mathrm{NHCH}_{2}-\mathrm{Fc}(23 \mathrm{mg}, 0.044$ $\mathrm{mmol}$ ) in $5 \mathrm{~mL}$ of $10 \%$ trifluoroacetic acid in dichloromethane was stirred at room temperature for 1 hour. The reaction solution was gently concentrated on a rotary evaporator, then $20 \mathrm{~mL}$ of dichloromethane was added and concentrated again. Addition of dichloromethane and subsequent concentration were repeated a total of 3 times in an effort to remove all residual trifluoroacetic acid. The resulting residue was dried under vacuum to give the title compound as a green solid (18 mg, 98\% yield). ${ }^{1} \mathrm{H}$ NMR $\left(\mathrm{CDCl}_{3}\right) \delta 7.3(\mathrm{~s}, 5 \mathrm{H}), 7.12(\mathrm{~s}, 2 \mathrm{H}), 5.4(\mathrm{~s}, 1 \mathrm{H}), 4.4$ - $4.0(\mathrm{~m}, 9 \mathrm{H}), 3.85(\mathrm{~m}, 2 \mathrm{H}), 3.5(\mathrm{~s}, 2 \mathrm{H}), 3.2(\mathrm{~s}, 2 \mathrm{H}), 2.85(\mathrm{~s}, 2 \mathrm{H})$; MS calc'd for $\mathrm{C}_{22} \mathrm{H}_{25} \mathrm{FeN}_{3} \mathrm{NaO}_{2} 442.1(\mathrm{M}+\mathrm{Na})^{+}$, found to be 442.1 . 
Experimental for Figure S14b: Synthesis of H-Leu- $\mathrm{NHCH}_{2}-\mathrm{Fc}$ for HPLC analysis.

To a solution of Fmoc-Leu-OH (126 mg, $0.36 \mathrm{mmol})$ and HATU $(123 \mathrm{mg}, 0.33 \mathrm{mmol})$ in DMF (1 mL) was added $\mathrm{NH}_{2} \mathrm{CH}_{2}$ - $\mathrm{Fc}(70 \mathrm{mg}, 0.33 \mathrm{mmol})$, and the resulting solution was stirred at room temperature for $30 \mathrm{~min}$. It was diluted with ethyl acetate $(100 \mathrm{~mL})$, and the organic layer was washed with water $(50 \mathrm{~mL} \times 3)$ and brine $(50 \mathrm{~mL})$, dried $\left(\mathrm{MgSO}_{4}\right)$, filtered, and concentrated to yield a brown oil, which was purified by silica gel chromatography using 50\% EtOAc/hexane as eluant to give Fmoc-Leu-NHCH $\mathrm{NHc}_{2}$ - $(98 \mathrm{mg}, 54 \%$ yield) as a yellow solid. MS calc'd for $\mathrm{C}_{32} \mathrm{H}_{34} \mathrm{FeN}_{2} \mathrm{NaO}_{3} 573.2(\mathrm{M}+\mathrm{Na})^{+}$, found to be 573.3.

A solution of Fmoc-Leu- $\mathrm{NHCH}_{2}-\mathrm{Fc}(81 \mathrm{mg}, 0.15 \mathrm{mmol})$ in $20 \%$ piperidine and DMF $(5 \mathrm{~mL})$ was stirred at room temperature for $30 \mathrm{~min}$. DMF was removed under reduced pressure and the resulting crude oil was purified by column chromatography using a mixture of $\mathrm{MeOH}$ and EtOAc (5:95) as eluant to give $\mathrm{H}-\mathrm{Leu}-\mathrm{NHCH}_{2}-\mathrm{Fc}$ as a yellow solid (33 $\mathrm{mg}, 67 \%$ yield). MS calc'd for calc'd for $\mathrm{C}_{17} \mathrm{H}_{24} \mathrm{FeN}_{2} \mathrm{NaO} 351.1(\mathrm{M}+\mathrm{Na})^{+}$, found to be 351.1 .
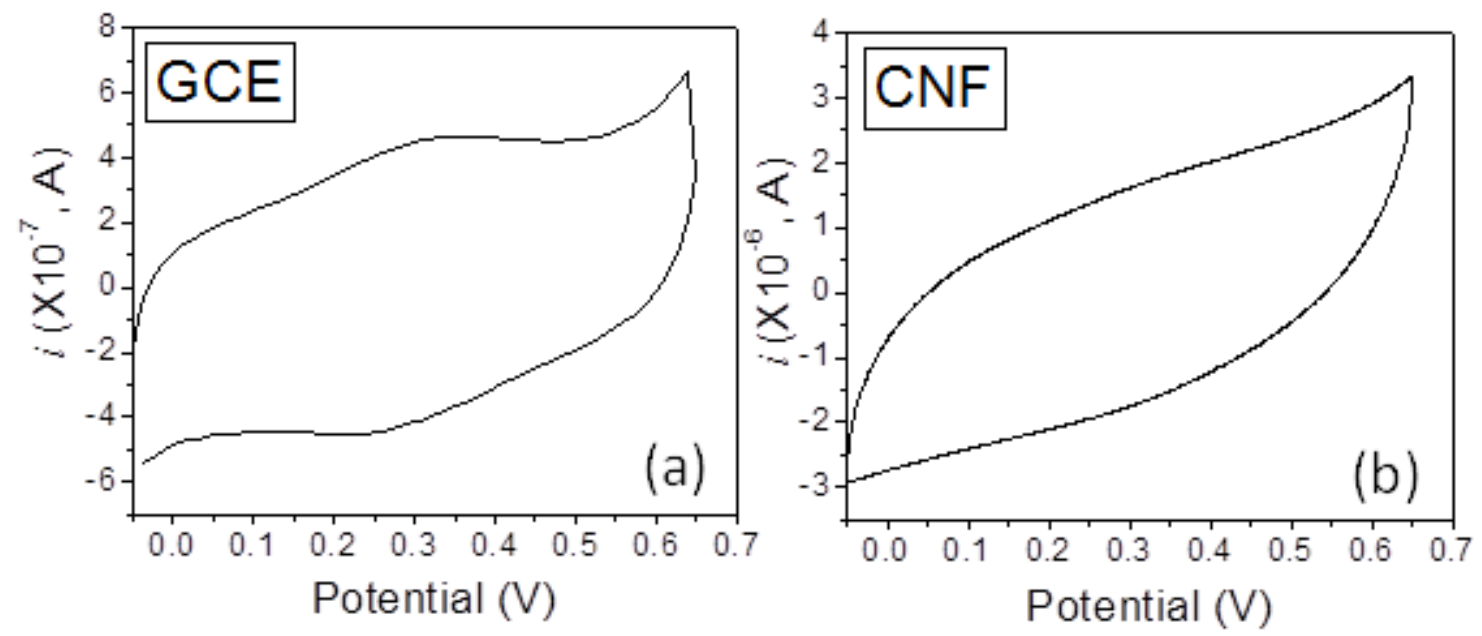

Figure S15. Comparison of cyclic voltammetric measurements of $\mathrm{H}_{2} \mathrm{~N}-\left(\mathrm{CH}_{2}\right)_{4}$-CO-Ala-Ala-AsnLeu-NHCH ${ }_{2}-\mathrm{Fc}$ immobilized on (a) a macro-GCE and (b) a VACNF NEA. The 
measurements were carried out at the scan rate of $50 \mathrm{mV} \mathrm{s}^{-1}$ in $1 \mathrm{~mL}$ of $1.0 \mathrm{M} \mathrm{KCl}$.

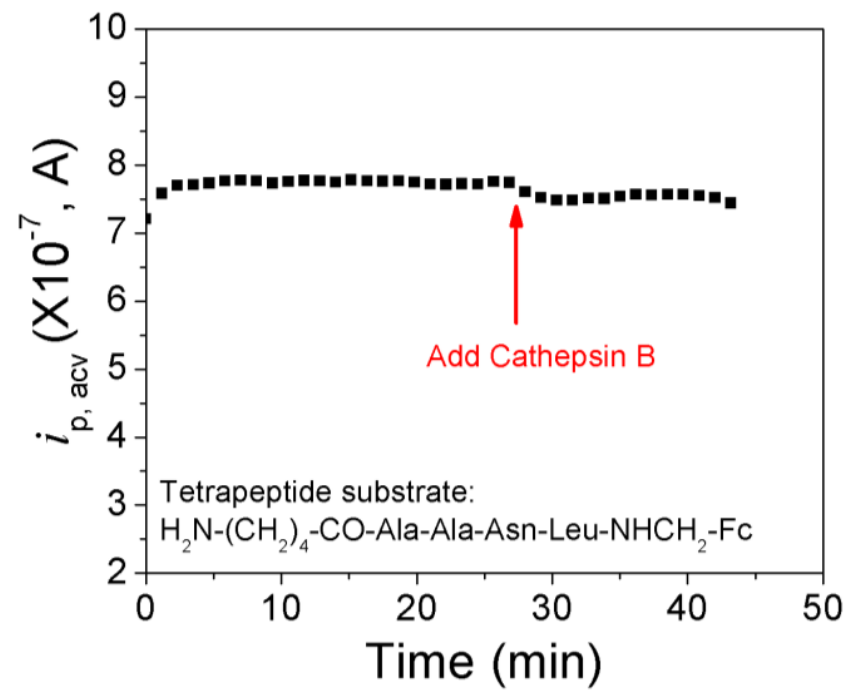

Figure S16. Preliminary specificity testing result. The change of the peak current $\left(i_{p, a c v}\right)$ of $\mathrm{H}_{2} \mathrm{~N}-\left(\mathrm{CH}_{2}\right)_{4}-\mathrm{CO}-\mathrm{Ala}-$ Ala-Asn-Leu-NH- $\mathrm{CH}_{2}-\mathrm{Fc}$ immobilized on a VACNF NEA in continuously repeated ACV measurements while 9.8 $\mathrm{ng} \mu \mathrm{L}^{-1}(338 \mathrm{nM})$ activated cathepsin B in $25 \mu \mathrm{L}$ of activation buffer consisting of $5 \mathrm{mM}$ DTT and $25 \mathrm{mM}$ MES (pH 5.0) was added into the electrochemical cell containing $250 \mu \mathrm{L}$ of $25 \mathrm{mM}$ MES (pH 5.0). 